\title{
Radiation Effects in Concrete for Nuclear Power Plants, Part II: Perspective from Micromechanical Modeling
}

\author{
Y. Le Pape ${ }^{\mathrm{a}, *}$, K.G. Field ${ }^{\mathrm{a}}$, I. Remec ${ }^{\mathrm{a}}$ \\ ${ }^{a}$ Oak Ridge National Laboratory, One Bethel Valley Road, Oak Ridge, TN 37831-6148
}

\begin{abstract}
The need to understand and the characterize the effects of neutron irradiation on concrete has become urgent because of the possible extension of service life of many nuclear power generating stations. Current knowledge is primarily based on a collection of data obtained in test reactors. These data are inherently difficult to interpret because materials and testing conditions are inconsistent. A micromechanical approach based on the Hashin composite sphere model is presented to derive a first-order separation of the effects of radiation on cement paste and aggregate, and, also, on their interaction. Although the scarcity of available data limits the validation of the model, it appears that, without negating a possible gamma-ray induced effect, the neutron-induced damage and swelling of aggregate plays a predominant role on the overall concrete expansion and the damage of the cement paste. The radiation-induced volumetric expansion (RIVE) effects can also be aided by temperature elevation and shrinkage in the cement paste.
\end{abstract}

\footnotetext{
${ }^{*}$ Corresponding author: lepapeym@ornl.gov (Y. Le Pape) 


\title{
Radiation Effects in Concrete for Nuclear Power Plants, Part II: Perspective from Micromechanical Modeling
}

\author{
Y. Le Pape ${ }^{\mathrm{a}, *}$, K.G. Field ${ }^{\mathrm{a}}$, I. Remec ${ }^{\mathrm{a}}$ \\ ${ }^{a}$ Oak Ridge National Laboratory, One Bethel Valley Road, Oak Ridge, TN 37831-6148
}

Keywords: biological shield, concrete, homogenization, irradiation, neutron, swelling

\section{Introduction}

The extension of operating lifetimes of commercial light water reactors (LWRs) requires a detailed evaluation of the knowledge gaps relevant for studying the performance of aging critical components. Large irreplaceable sections of most nuclear power generating stations include concrete. An analysis jointly performed by an expert panel from the Department of Energy (DOE), the Nuclear Regulatory Commission (NRC), the industry and academia recently identified the urgent need to develop a consistent body of knowledge on the irradiation of concrete (Graves et al., 2014). Most of the publicly available data on the effect of neutron and gamma irradiation on concrete was developed in the 1960s and 1970s. The most frequently quoted study of the irradiation effects on concrete mechanical properties is Hilsdorf et al. (1978). The inherent difficulty with evaluating the compiled literature is the number of variables inherent in an irradiation experiment; these vari-

\footnotetext{
*Corresponding author: lepapeym@ornl.gov (Y. Le Pape)
} 
ables include the different materials used (cement and aggregate); mix proportions; curing and environmental conditions (temperature and relative humidity) during irradiation; internal moisture content; and testing conditions (neutron fluxes and spectra, in particular). The relevance of the collected data for the long-term operation of LWRs is now being questioned. A recent re-evaluation pointed towards those variabilities and deficiencies in context of previously presented literature (Kontani et al., 2013). It was noted in par-

ticular that most neutron irradiation experiments beyond $3.0 \times 10^{19} \mathrm{n} / \mathrm{cm}^{2}$ fluence were conducted at high temperatures (above $150^{\circ} \mathrm{C}$ ) and using either aluminous cement or liquid glass aggregate (Dubrovskii et al., 1966; Elleuch et al., 1971, 1972).

The objectives of the present work are: (1) to estimate the radiation levels in concrete structures up to 80 years of service in LWRs, (2) to extend the Hilsdorf et al. study with data not previously reviewed in open literature, (3) to outline the possible mechanisms for irreversible damage induced in irradiated concrete structures, and (4) to develop a micromechanical model for understanding the interactions between the cement paste and aggregate in the presence of irradiation. Objectives 1-3 are detailed in our companion paper Field et al. (2014). This article is devoted to an in-depth investigation into objectives $3-4$.

\section{Micromechanical Model}

Concrete is a multiscale and multiphase (solid, liquid, and gas) composite material. The effects of irradiation on the constituents of concrete and cement-like materials or on the composite material itself are still not fully 
understood, although there have been some systematic studies of the effects of irradiation on concrete and the constituting cement paste and aggregate (Kelly et al., 1969; Elleuch et al., 1972). The theory of homogenization of random media, also called micromechanics, is an adequate tool to go beyond qualitative interpretation. Micromechanics makes it possible to assess some hypotheses about the degradation mechanisms in the constituents of concrete and the potential interactions of the constituents. Modern homogenization theory derives from the pioneer works of Eshelby (1957), which describes the elastic fields of an ellipsoidal inclusion embedded in an infinite matrix. Eshelby's problem was extended to a variety of related problems to bound (Hashin and Shtrikman, 1963; Kröner, 1977) or estimate the elastic properties of composite materials (Hershey, 1954; Mori and Tanaka, 1973) and (Christensen and Lo, 1979; Hervé and Zaoui, 1993; Le Roy, 1995) for multilayered inclusions composites. Applications of these homogenization concepts for modeling the elasticity, creep, shrinkage and alkali-silica reaction-induced swelling of cement as a multiscale material has been successfully demonstrated by many authors including (Bernard et al., 2003; Pichler et al., 2007; Dormieux et al., 2006; Ben Haha, 2006; Sanahuja et al., 2007; Le Pape et al., 2009).

\subsection{Homogenized Elastic Properties}

In the classical sense of the mean field homogenization theory, the effective properties (e.g., the elastic stiffness tensor) and macroscopic swelling are derived as a weighted average of the constituent properties, their volume fractions and the localization tensors (i.e., by describing the relationship between the local strain/stress and the macroscopic strain/stress). Hence, 
the homogenization theory does not require an extensive description of the three-dimensional microstructure of irradiated concrete, which is not available in the existing literature since only average quantities (strain, stress or localization tensors) by phase (i.e., constituent) are estimated. The microstructure is idealized by a set of particles or inclusions (typically spheres, spheroids or multilayered spheres) embedded either in a matrix (Mori-Tanaka homogenization scheme (Mori and Tanaka, 1973)) or in the effective unknown medium (i.e., self-consistent scheme (Kröner, 1977) generally more applicable to polycrystalline materials).

Homogenization theory assumes the separation of scales; i.e., the size of the constituents must be significantly smaller than the size of the representative volume. This assumption is difficult to assess strictly with concrete since a continuous size distribution is the basis for good design of concrete in order to maximize the compactness of the mix. In practice, two to four different scales can be distinguished for cement and concrete-like materials. Here, the cement paste, including the unhydrated cement, the hydration products, the capillary pores and fine particles (silica fume, filler, fine form aggregate), is considered as the first scale. Aggregate can be either separated in a mortar scale, including sand, and a concrete scale including coarse aggregate, or accounted as the whole in the subsequent steps of the homogenization process. Because of the lack of knowledge on the possible effects of irradiation on the properties of the interfacial transition zone, and unless otherwise specifically stated in the text, the cement paste and aggregate are assumed perfectly bonded at their interface for the sake of simplicity. The homogenization schemes pertinent for concrete depend on the hydra- 
tion degree (Sanahuja et al., 2007) and the nature of the properties sought. For hardened concrete, both Mori-Tanaka(Mori and Tanaka, 1973) and selfconsistent schemes (Kröner, 1977; Christensen and Lo, 1979) provide close approximations of the concrete elastic properties. In this paper, Hashin composite sphere is assumed to model concrete: the inner sphere corresponds to the aggregate, and the outer sphere to the matrix (Fig. 1).

It is worth noting that the effective bulk modulus solution obtained by the self-consistent scheme, the Hashin composite model and Hashin-Shtrikman's lower bound (variational approach) are consistent. The effective bulk modulus of concrete, $k_{c}$, is given by:

$$
k_{c}=k_{m}+\frac{f_{a}\left(k_{a}-k_{m}\right)}{1+\left(1-f_{a}\right) \frac{k_{a}-k_{m}}{k_{m}+\frac{4}{3} \mu_{m}}}
$$

Although Christensen and Lo (1979) (CL scheme) derived the effective shear modulus $\mu_{c}$, for the sake of simplicity, the Mori-Tanaka scheme(Mori and Tanaka, 1973) is adopted in the following:

$$
\mu_{c}=\mu_{m}+\frac{f_{a}\left(\mu_{a}-\mu_{m}\right)}{1+\left(1-f_{a}\right)\left[\frac{\mu_{a}-\mu_{m}}{\mu_{m}+\frac{\mu_{m}\left(9 k_{m}+8 \mu_{m}\right)}{6\left(k_{m}+2 \mu_{m}\right)}}\right]}
$$

Equation (2) provides a close approximation of the CL scheme for usual elastic properties of inclusions and matrix relevant for concrete. In equations (1) and (2), the subscripts ${ }_{c},{ }_{a}$ and ${ }_{m}$ correspond, respectively, to the concrete, the aggregate and the cement paste (referred here as the matrix). $f_{a}$ is the volume fraction of aggregate derived from the mix composition. $k_{i=c, a, m}$ and $\mu_{i=c, a, m}$ are the bulk and shear moduli of the corresponding undamaged material, i.e., $k_{i}=\frac{1}{3} E_{i} /\left(1-2 \nu_{i}\right)$ and $\mu_{i}=\frac{1}{2} E_{i} /\left(1+\nu_{i}\right)$, with $E_{i}$ and $\nu_{i}$ being 
the Young modulus and the Poisson ratio. Both previous equations are valid with damaged elastic properties noted in the following $\tilde{k}_{i=c, a, m}$ and $\tilde{\mu}_{i=c, a, m}$.

\subsection{Elastic Properties of Cracked Cement Paste}

Cement paste elastic properties depend on the level of pre-existing damage caused by prior loading (mechanical actions, restrained or differential shrinkage and thermal expansion). The type of damage considered here is micro-cracking (i.e., cracks of about the characteristic size of large capillary pores of $\approx 10-100$ microns). Crack closure or face interactions are ignored (i.e., no hysteresis effect is considered). For the sake of simplicity, a cracked solid with randomly oriented penny-shaped (circular) cracks is assumed. This evaluation of the effective properties of a cracked medium follows Budiansky and O'Connell (1976)'s analytical model: studying the loss of potential energy introduced by an isolated crack in an infinite body having the effective properties of the cracked body (i.e., the self-consistent scheme) leads to defining the bulk modulus of the cracked cement paste, $\tilde{k}_{m}$, by:

$$
\frac{\tilde{k}_{m}^{S C}}{k_{m}}=1-\frac{2 N\left\langle a^{3}\right\rangle\left\langle f\left(\tilde{\nu}_{m}\right)\right\rangle}{3\left(1-2 \tilde{\nu}_{m}\right)}
$$

Where $N, a$ and $\tilde{\nu}$ denote, respectively, the number of cracks, a characteristic linear dimension for each crack and the effective Poisson coefficient of the cracked material. $f$ is a function that depends on $\tilde{\nu}$ and also on the geometry of the cracks. Assuming an ellipsoidal-shaped crack makes it possible to derive an explicit solution:

$$
\frac{\tilde{k}_{m}^{S C}}{k_{m}}=1-\underbrace{\frac{16}{9}\left(\frac{1-\tilde{\nu}_{m}^{2}}{1-2 \tilde{\nu}_{m}}\right)}_{\zeta_{k}} \eta
$$


Where $\eta$ is the crack-density parameter defined by $\frac{2 N}{\pi}\left\langle\frac{A^{2}}{P}\right\rangle$, and $A$ and $P$ are, respectively, the surface area and the perimeter of the crack. The crack density reads:

$$
\eta=N\left\langle a^{3}\right\rangle=\frac{45}{16} \frac{\left(\nu_{m}-\tilde{\nu}_{m}\right)\left(2-\tilde{\nu}_{m}\right)}{\left(1-\tilde{\nu}_{m}^{2}\right)\left[10 \nu_{m}-\tilde{\nu}_{m}\left(1+3 \nu_{m}\right)\right]}
$$

Eq. (5) only depends on the Poisson ratios of the uncracked and cracked bodies. The effective shear modulus of the cracked medium is given by:

$$
\frac{\tilde{\mu}_{m}^{S C}}{\mu_{m}}=1-\underbrace{\frac{32}{45} \frac{\left(1-\tilde{\nu}_{m}\right)\left(5-\tilde{\nu}_{m}\right)}{2-\tilde{\nu}_{m}}}_{\zeta_{\mu}} \eta
$$

$\tilde{\nu}_{m}$ is a decreasing function of $\eta$. When $\eta \rightarrow 9 / 16$, the effective elastic properties of the cracked medium tend to zero. This effect is related to the interaction between the cracks (sometimes described as a "percolation effect", typical of the self-consistent scheme). There is no assurance that the value of 9/16 is an actual percolation threshold though. A smoother decrease of the effective elastic properties with the crack density can be derived using the Mori-Tanaka scheme (Benveniste, 1987):

$$
\frac{\tilde{k}_{m}^{M T}}{k_{m}}=\frac{1}{1+\zeta_{k} \eta} \text { and } \frac{\tilde{\mu}_{m}^{M T}}{\mu}=\frac{1}{1+\zeta_{\mu} \eta}
$$

In theory, infinite values of crack density can be achieved with the MoriTanaka approach because no percolation threshold is determined. The MoriTanaka and self-consistent schemes only provide similar results for small values of crack density (equivalent to the dilute scheme (Walsh, 1965)). Significant discrepancies are observed for crack densities higher than 0.1. Hence, the crack density should essentially be understood as a comparison index between different states of damage. Consistent comparison requires 
the use of the same homogenization scheme. In the following, Budiansky and O'Connell's approach will be adopted. Hence, the superscript ${ }^{S C}$ will be dropped: $\tilde{k}_{m}:=\tilde{k}_{m}^{S C}$.

\subsection{Swelling of Concrete as a Composite Material}

Following Le Roy (1995) andLe Roy and Granger (1995) shrinkage model and Ben Haha (2006) alkali-silica reaction-induced swelling model, the Hashin composite sphere model allows deriving the swelling of concrete. The resolution of the elastic problem is detailed in Hobbs (1969) and Le Roy (1995). The overal linear expansion or contraction of concrete is given by the expression

$$
\varepsilon_{c}=\beta \varepsilon_{a}+(1-\beta) \varepsilon_{m} \text { with } \beta=\beta\left(f_{a}, \tilde{k}_{m}, \tilde{\mu}_{m}, \tilde{k}_{a}\right)
$$

Where $\beta$ is the expansion transfer coefficient from the aggregate to the concrete. The transfer coefficient for the matrix is given by $1-\beta$. The value of $\beta$ is a function of the effective elastic properties of the aggregate and the cement paste. Different expressions might be found, depending on how shear stress effects are accounted for in the resolution. The more general form is given by the relation

$$
\beta=\frac{f_{a} \tilde{k}_{a}\left(3 \tilde{k}_{m}+4 \tilde{\mu}_{m}\right)}{\tilde{k}_{m}\left(3 \tilde{k}_{a}+4 \tilde{\mu}_{m}\right)-4 f_{a} \tilde{\mu}_{m}\left(\tilde{k}_{m}-\tilde{k}_{a}\right)}
$$

Using the bulk and shear moduli of the respective components, if no shear stress is assumed in the matrix (i.e., $\nu_{m}=\nu_{a}$ ), an even simpler expression can be derived (Hobbs, 1969; Ben Haha, 2006):

$$
\beta=\frac{2 f_{a} \tilde{k}_{a}}{\tilde{k}_{m}+\tilde{k}_{a}+f_{a}\left(\tilde{k}_{a}-\tilde{k}_{m}\right)}
$$


Although Eq. (10) is not strictly applicable to the case of a cracked paste $\left(\tilde{\nu}_{m} \in\left[0 ; \nu_{m}\right]\right)$, it provide a practical estimation of the actual expansion transfer coefficient with a maximum error estimated below $10 \%$ for a fully cracked paste. Interestingly, if the effective modulus of the cement paste is signifi-

cantly degraded (i.e., $\tilde{k}_{m}<<\tilde{k}_{a}$ ), the previous expression only depends on the volume fraction of aggregate:

$$
\beta_{\max }=\lim _{\tilde{k}_{m} \rightarrow 0} \beta=\frac{2 f_{a}}{1+f_{a}}
$$

This expression provides an upper-bound value for the transfer coefficient. With a typical aggregate volume fraction of 0.6 to $0.75, \beta_{\max }$ varies in the range of 0.75 to 0.86 . The second limit case of interest is when the elastic bulk modulus of the irradiated aggregate decrease to a level similar to that of the cement paste (i.e., $\tilde{k}_{m} \approx \tilde{k}_{a}$ ); Eq. (10) reads:

$$
\beta_{\min }=\lim _{\tilde{k}_{m} \rightarrow \tilde{k}_{a}} \beta=f_{a}
$$

\section{Radiation-Induced Volumetric Change and Damage Mechanisms}

\subsection{Cement Paste}

Compton scattering effect reduces gamma ray energy to a low level unlikely to have strong interaction with the solid phases of the cement paste, although the Si-O bond of C-S-H may be slightly decomposed due to its covalent nature (Maruyama et al., 2012). However, the energy level is sufficient to develop water radiolysis generating hydrogen and hydrogen peroxide (Bouniol and Aspart, 1998). Post-irradiation X-ray diffraction seems to indicate the decomposition of metastable peroxide by subsequent carbonation into calcite at the expense of crystalline phases (i.e., Portlandite, ettringite 
and anhydrous clinker phases) (Łowińska-Kluge and Piszora, 2008; Vodák et al., 2010). The result is a change in the pore size distribution at the expense of larger pores and a reduction of the average pore diameter (Bouniol, 2004; Vodák et al., 2005, 2011). Łowińska-Kluge and Piszora (2008) observed the formation of pseudomorphoses of ordinary cement paste above 130 MGy and sample destruction at 836 MGy (i.e., well beyond the effective dose expected in a nuclear reactor biological shield). Neutrons are unlikely to develop significant damage in the cement paste because its poor crystallinity and high porosity prevent any defect accumulation (Kontani et al., 2013).

The rise of temperature during irradiation experiments primarily results in a loss of free water content, leading to drying shrinkage. Depending on the geometry of the specimen and the kinetics of the moisture transport, a differential drying shrinkage leads to compression in the bulk of the material and tension on the drying surface, causing cracking. Cement paste mechanical properties are affected by drying (Pihlajavaara, 1974). "In a paste dried or cured at elevated temperatures $\left(60^{\circ} \mathrm{C}\right.$ or greater), the structure collapses toward a denser (less porous) and more stable configuration with fewer large gel pores, resulting in a greater amount of capillary porosity" (Jennings et al., 2007).

The temperature in biological shield buildings or reactor pressure vessel support structures is bounded by design at around $65^{\circ} \mathrm{C}\left(150^{\circ} \mathrm{F}\right)$ with potential peak values at $93^{\circ} \mathrm{C}\left(200^{\circ} \mathrm{F}\right)$, but the temperature during accelerated irradiation experiments can exceed $150^{\circ} \mathrm{C}$. Potential effects must be accounted. Naus (2005) summarized the effect of temperature on cement pastes: "Evaporable water is driven off until at a temperature of about $105^{\circ} \mathrm{C}$ 
all evaporable water will be lost, given a sufficient exposure period. At temperatures above $105^{\circ} \mathrm{C}$, the strongly absorbed and chemically combined water (i.e., water of hydration) are gradually lost from the cement paste hydrates, with the dehydration essentially complete at $850^{\circ} \mathrm{C}$. Then, from $105^{\circ} \mathrm{C}$ onward, the evaporation proceeds at a faster rate with water being expelled from concrete near the surface as a result of above-atmospheric vapor pressure (i.e., steam flow). At $120^{\circ} \mathrm{C}$ the expulsion of water physically bound in the smaller pores, or chemically combined, initiates and continues up to about $500^{\circ} \mathrm{C}$ where the process is essentially complete. From $30^{\circ} \mathrm{C}$ to $300^{\circ} \mathrm{C}$, in conjunction with evaporation, dehydration of the hardened cement paste occurs (first stage) with the maximum rate of dehydration occurring at about $180^{\circ} \mathrm{C}$ (tobermorite gel is stable up to a temperature of $150^{\circ} \mathrm{C}$ )". Noumowé (1995) also mentions the possibility of endothermic decomposition of the remaining gypsum that has not been consumed by the hydration reactions.

In summary, damage of cement paste caused by irradiation can result from drying (including gamma heating), gamma-induced carbonation and heat. Hence, the effective mechanical properties of irradiated cement paste can be described by the generic function:

$$
\left(\tilde{k}_{m}, \tilde{\mu}_{m}\right)=\mathcal{F}(\underbrace{\frac{\Delta m}{m_{0}}(\gamma, T, R H)}_{\text {Loss of Moisture Content }}, \overbrace{\Delta \varphi(\gamma)}^{\text {Porosity Change }}, \underbrace{T}_{\text {Thermal Damage }})
$$

where $\Delta m / m_{0}$ is the loss of weight function of the gamma ray dose $\gamma$, the temperature $T$ during irradiation and the ambient relative humidity $R H . \Delta \varphi$ denotes the possible porosity change resulting from the radiolysis-induced gamma ray exposure. The free volumetric expansion or contraction of the 
cement paste is caused by the drying shrinkage and the thermal expansion:

$$
\varepsilon_{m}=\underbrace{\varepsilon_{m}\left(\frac{\Delta m}{m_{0}}(\gamma, T, R H)\right)}_{\text {Drying Shrinkage }}+\underbrace{3 \alpha_{m}(T) \Delta T}_{\text {Thermal Expansion }}
$$

Drying shrinkage is known to be a partly reversible, partly irreversible, mechanism (Mehta and Monteiro, 2006). During irradiation experiments, the temperature increase can accentuate the irreversibility by promoting the release of chemically bound water. The thermal expansion coefficient of cement paste depends on the moisture content and the temperature. Emanuel and Leroy Hulsey (1977) found that the expansion coefficient of ordinary Portland cement (water to cement ratio 0.12 and 0.40 , aged $0-6$ months) is maximum around $20 \mu \mathrm{m} / \mathrm{m} /{ }^{\circ} \mathrm{C}$ when the relative moisture content (saturation degree) is about $0.60-0.70$. The initial value at saturation is around $11 \pm 2 \mu \mathrm{m} / \mathrm{m} /{ }^{\circ} \mathrm{C}$. The value at complete drying is slightly higher than at saturation: $\approx 11-14 \mu \mathrm{m} / \mathrm{m}^{\circ} \mathrm{C}$. The maximum value of the coefficient for cement paste decreases with age to approximately $80 \%$ of that for specimens 6 months old and younger. Bažant and Kaplan (1996) report experimental expansions on ordinary Portland cement (Crowley, 1956; Philleo, 1958; Harada et al., 1972; Cruz and Gillen, 1980): "Initially the hardened cement paste expands on heating up to approximately $150{ }^{\circ} \mathrm{C}$, the maximum expansion being on the order of $0.2 \%$. Expansion ceases between $150{ }^{\circ} \mathrm{C}$ and $300{ }^{\circ} \mathrm{C} "$ (Naus, 2010). Of the four cement pastes reported, the ordinary Portland cement had the lowest expansion (about 1.5\%) whereas the blended cement pastes (silica fume or fly ash) reached about 3\% of expansion. 


\subsection{Aggregate}

For the same reason that the low energy from gamma rays are not considered as a major source of damage to the cement paste skeleton, aggregate are judged unlikely to be affected, although siliceous aggregate may be slightly decomposed (Kontani et al., 2010). The amount of absorbed water (1\% to $2.5 \%)$ and crystal bonded water $(0.5 \%$ to $1.5 \%)$ is limited but may lead to radiolysis and evaporation by gamma heating.

Since concrete aggregate are obtained by natural or artificial fragmentation of a parent rock, their well crystalized mineral structures make them susceptible to neutron damage, and, particularly, to amorphization. $\alpha$-quartz amorphization was particularly studied under ion-beam irradiation (Bonnet et al., 1994; Harbsmeier and Boise, 1998; Manzano-Santamaría et al., 2012). The final volumetric expansion can reach 14-15\% (Seeberger and Hilsdorf, 1982). This transformation is irreversible and can be observed after cooling. Silicates are present in many other forms of aggregate, suggesting that similar swelling mechanism could also occur. Radiation-induced volumetric expansion (RIVE) observed on numerous varieties of aggregate is the subject of our companion paper (Field et al., 2014). Another important group of common minerals found in concrete aggregate is the carbonate rock that forms the dolomitic and calcitic limestone. Calcite seems insensitive to irradiation effects and, as a result, so are dolomites or limestones containing minor impurities (Seeberger and Hilsdorf, 1982). In contrast, Gray (1971) reported a substantial reduction of the post-irradiation elastic properties and, signifi-

cant expansion in limestone samples irradiated beyond $2.5 \times 10^{19} \mathrm{n} / \mathrm{cm}^{2}$. It should be kept in mind that, per ASTM C294-12, the term limestone is not 
restricted to pure or almost pure dolomite and that a large proportion of impurities may include noncarbonated minerals like quartz, chert, clay minerals, organic matter, gypsum or sulfides. As an illustration, Grattan-Bellew and Chan (2013) recently reported that the so-called alkali-carbonate reaction of a dolomitic limestone in Canada actually resulted from the presence of cherty silica. Similar observations were previously reported by Katayama (2004, 2010) who introduced the term "concealed ASR".

Commonly used aggregate for concrete are stable up to $300-350{ }^{\circ} \mathrm{C}$ (Naus, 2005).

In summary, neutron irradiation is the most prominent damage source of aggregate. The effective mechanical properties of irradiated aggregate can be written:

$$
\left(\tilde{k}_{a}, \tilde{\mu}_{a}\right)=\mathcal{F}(n)
$$

where $n$ is the neutron fluence. In addition, the swelling of the aggregate during an irradiation test can solely result from thermal expansion and possible phase change produced by irradiation. Griffith (1936) showed that the expansion coefficient of aggregate depends on its nature and on its silica content. The thermal expansion coefficient of ordinary and high-performance concrete increases by $20 \%$ to nearly $50 \%$ between $20^{\circ} \mathrm{C}$ and $275^{\circ} \mathrm{C}$ (Noumowé, 1995). For temperatures varying between $20^{\circ} \mathrm{C}$ and $100^{\circ} \mathrm{C}$, the thermal expansion coefficient ranges from 9.0 and $10.0 \mu \mathrm{m} / \mathrm{m} /{ }^{\circ} \mathrm{C}$ for quartz and sandstone and from 5.5 and $11.8 \mu \mathrm{m} / \mathrm{m} /{ }^{\circ} \mathrm{C}$ for limestone, although values below 5.0 have been observed particularly, with pure limestones (Johnson and Parsons, 1944). Granite and basalt exhibit lower expansion coefficients around $7.0 \mu \mathrm{m} / \mathrm{m} /{ }^{\circ} \mathrm{C}$. These data are provided as broad indication of the thermal 
expansion coefficient scatter resulting from the actual complex mineralogy of each specific aggregate.

Browne (1967) provides some experimental data of the thermal expansion coefficients for different types of aggregate. The important scattering is attributed by the authors to the strong anisotropy of the tested minerals. Kelly et al. (1969) present thermal expansion coefficient measured on limestones and siliceous aggregate before and after neutron irradiation between $1.1 \times 10^{19} \mathrm{n} / \mathrm{cm}^{2}$ and $2.5 \times 10^{19} \mathrm{n} / \mathrm{cm}^{2}$. Although not measured on the same samples, almost no variation of the thermal expansion coefficient is observed except for two limestones (referred as "high mag." and "low mag." by the authors, which could indicate Magnesian limestone, i.e., a form of dolomite) for which the expansion coefficients doubled and nearly tripled, respectively.

The volumetric free swelling of aggregate during irradiation reads:

$$
\varepsilon_{a}=\underbrace{\varepsilon_{a}(n)}_{\text {Irradation Swelling }}+\underbrace{3 \alpha_{a}(T) \Delta T}_{\text {Thermal Expansion }}
$$

\subsection{Matrix-Aggregate Interaction}

The cement paste-aggregate interaction results from the restraining effect of any volumetric expansion of either of the two constituents produced by the contrast of elastic properties between them. Paste shrinkage and aggregate expansion causes tensile stress in the quasi-brittle hardened cement paste and, eventually, microcracking. 


\section{Interpretation of Literature Data}

\subsection{Experiments Conducted by Elleuch et al. (1972)}

Elleuch et al. (1972) conducted irradiation experiments on concrete; serpentine aggregate, which has a high silica and magnesium oxide content); and pure aluminous cement paste, which has a high calcium aluminate content compared to ordinary Portland cement). The water-to-cement ratio for the cement paste is 0.25 , whereas the water-to-cement ratio for concrete is 0.38. The cement to aggregate ratio by mass is 1:3.85. Assuming that the cement density is 3.12 (the default value), the total volume fraction of aggregate is estimated at about 0.66 . The cement paste and concrete molds were placed in water heated at $60^{\circ} \mathrm{C}$ for 24 hours before being stored for curing at $20^{\circ} \mathrm{C}$ and $60 \%$ relative humidity. The thermal treatment improves the stability of the crystalline structure of the aluminate hydrates. After 3 months of curing, the samples were gradually dried for one week at $250^{\circ} \mathrm{C}$ with the aim of eliminating the water in the sample and lessening the harmful effects of the sudden temperature rise at the beginning of the irradiation tests. The authors observed numerous small cracks on the surface of the pure cement paste samples, probably resulting from differential drying shrinkage. Irradiation doses received by the different materials ranged approximately from $1.2 \times 10^{19}$ to $1.1 \times 10^{20} \mathrm{n} / \mathrm{cm}^{2}(E>1 \mathrm{MeV})$. The temperature during irradiation varied from one testing box to the other. The location of the box in the testing rig also influenced the actual temperature in the specimens. For concrete, temperature during irradiation varied from $150^{\circ} \mathrm{C}$ to $240^{\circ} \mathrm{C}$ with most experiments at $210^{\circ} \mathrm{C}$; for cement paste, the temperature varied between $140^{\circ} \mathrm{C}$ and $280^{\circ} \mathrm{C}$; and finally, for serpentine aggregate, the 
temperature varied between $150^{\circ} \mathrm{C}$ and $240^{\circ} \mathrm{C}$.

\subsection{Pulse velocity}

Pulse wave velocity is a nondestructive technique that provides an indirect measurement of the dynamic elastic properties of a material. ASTM C59709 defines how the technique is used for concrete. The relation between the pulse velocity $v$ and the (isotropic) dynamic properties $E_{d y n}$ and $\nu_{d y n}$ is given by:

$$
v=\sqrt{\frac{E_{d y n}\left(1-\nu_{d y n}\right)}{\rho\left(1+\nu_{d y n}\right)\left(1-2 \nu_{d y n}\right)}},
$$

where $\rho$ is the density of the material. Elleuch et al. (1972) have measured post-irradiation pulse velocities of serpentine aggregate, pure cement paste and concrete at different fluence levels. Figure 2 displays the experimental data points after digitizing the plot that was originally published. The data on the far left portion of the plot at '0-'fluence were obtained on pristine samples at room temperature before the pre-drying treatment. All post-irradiation measurements exhibit a significant drop of the pulse wave velocity for each constituent compared to the pre-irradiation results. Best linear fits show that there is almost no additional decrease in pulse velocity with increasing neutron fluence in the pure cement paste, while significant gradual reduction of the dynamic property of the serpentine is observed. The decreasing pulse rate in concrete is about the average of the decreasing pulse rate of the cement paste and the serpentine. Pre-dried samples subjected to

further thermal cycles provide an interesting baseline for comparison: The loss of pulse velocity is similar for a pure paste sample; no loss is observed for serpentine aggregate; and the loss is higher for concrete specimens, suggest- 
ing an interaction mechanism between the aggregate and the cement paste. The apparent absence of effect from irradiation on the pulse velocity of pure cement paste suggests that the thermal treatment at $250^{\circ} \mathrm{C}$ is the source of the produced damage. The authors also report that "the changes in weight of the pure cement pastes are of the same order after irradiation or storage at a temperature during the same time. The weight changes of the concrete are, therefore, solely due to dehydration of the pure cement paste." The same observation was made for concrete samples. Hence, no additional loss of water occurred in the cement paste samples during irradiation. Furthermore, fully pre-dried cement paste specimens were not affected by further exposure to neutrons.

Dubrovskii et al. (1968) conducted experiments on serpentine concrete that found that at an integrated neutron flux of 1.3 to $1.6 \times 10^{21} \mathrm{n} / \mathrm{cm}^{2}$, the residual elastic modulus ("the strain modulus") was about $40 \%$ of its initial value, suggesting a reduced rate of loss of elastic properties at higher fluence than suggested by the linear fit on Fig. 2.

Based on the pulse wave velocity, the cracking density in cement can be evaluated using certain assumptions and following Budiansky and O'Connell's approach. The reason for evaluating the crack density is to compare the damage in the pure cement specimens and the cement paste in concrete. Since there is no effect of neutron irradiation on the pre-dried pure cement sample, any additional damage in the cement paste in concrete can only result from interaction with the embedded aggregate. Two assumptions are needed to compare the cracking densities: First, the undamaged elastic properties of the cement paste in pure paste and the concrete specimens are assumed 
to be comparable, although their water-to-cement ratios are not identical, respectively equal to 0.25 and 0.38 . Theses values are low, below the critical water-to-cement ratio needed for full hydration. Assuming that Powers and Brownyard (1948)'s equations hold for aluminous cement, the capillary porosity governing the elastic properties of the cement paste can be evaluated at about $6.3 \%$ and $7.7 \%$. Hansen (1986) derives the capillary porosity $\varphi=(w / c-0.36 m) /(w / c+0.32)$ as a function of the water-to-cement ratio $w / c$ with $m=(w / c) / 0.42$ the maximum achievable degree of hydration. Hence, the comparison, if not exact, is still fair. Second, the pulse velocity is a function of Young's modulus, Poisson's ratio and density. Assumptions must be made about the undamaged Poisson ratio and the density of the cement paste under irradiation. Note that the post-irradiation damaged Poisson ratio results from the calculation of the crack density. Without further information, a default value of 0.2 is chosen for the undamaged cement paste. Because, the swelling or contraction of the different irradiated materials is lower than $\pm 1 \%$, density change is ignored. The cracking density of pure cement paste samples results immediately from the application of equations (4) and (5). The evaluation of the crack density of the concrete paste requires the estimation of its effective bulk modulus by inverse homogenization using an approximation of equation (1).

Fig. 3 (Left) summarizes the calculations of the estimated crack densities in pure cement paste samples and in the paste surrounding the aggregate. The crack density is defined in the sense of Budiansky and O'Connell self-consistent scheme with full damage (i.e., total loss of stiffness) obtained at $\eta=9 / 16$. For pure cement paste, the crack density of irradiated pre- 
dried specimens is significantly higher than the crack density of the reference pristine specimens. The relative increase rate of crack density is obviously comparable to the relative decrease of pulse wave velocity. Interestingly, there is no correlation between the estimated crack density in pure cement paste sample and the temperature measured during the irradiation tests [Fig. 3 (Right)]. The temperature during these tests rarely exceeded the temperature of the prior thermal treatment $\left(250^{\circ} \mathrm{C}\right)$. For comparable fluence level, the crack density in the cement paste surrounding the concrete aggregate is always higher than the crack density in the pure cement paste sample. The difference can be explained by the interaction with the aggregate that restrains the paste shrinkage and expands, causing the paste microcracking. Best linear fit shows a significant increase of the cracking density in the concrete paste with the received fluence. The increase rate is about 3.5 times higher than that of the pure cement samples proving stronger interactions as the total fluence increases. The post-irradiation crack densities estimated for the concrete paste are important (higher than 0.4 ) and above $70 \%$ of the theoretical "full-damage" threshold, suggesting that the residual mechanical properties of the paste in concrete specimens were greatly affected after the irradiation experiments.

\subsection{Dimensional Change}

Post-irradiation measurements of the length change were conducted on pure paste, serpentine and concrete specimens. Gradual expansion of the concrete and the serpentine specimens is observed as the fluence level increases. The maximum residual expansion (at $1.0 \times 10^{20} \mathrm{n} / \mathrm{cm}^{2}$ ) was about $+0.7 \% \pm 0.2 \%$ and $+0.6 \% \pm 0.1 \%$ for concrete and serpentine, respectively. 
There is no discernable trend describing the residual shrinkage measured on pure cement paste after irradiation: the observed length change varies from $-0.1 \%$ to $-0.6 \%$. Pure paste samples subjected to thermal cycles exhibited shrinkage that was similar to shrinkage in irradiated samples.

Fig. 4 shows the correlation between the expansion of concrete and serpentine aggregate; data is compared at similar fluence levels. For each fluence related to a given serpentine expansion, all corresponding concrete expansion data in the interval of $\pm 1.5 \times 10^{+18} \mathrm{n} / \mathrm{cm}^{2}$ were retained. A majority of the plot shows that the residual expansion of concrete is larger than the expansion of the serpentine. This result is counterintuitive since the aggregate are subjected to swelling, while the cement paste is shrinking. The best linear regression finds $\varepsilon_{c}=0.84 \varepsilon_{a}+0.13 \%$, where $\varepsilon_{c}$ and $\varepsilon_{a}$ are the length change of concrete and serpentine, respectively. Interestingly, the slope of the linear regression is close to the estimated maximum value of the expansion transfer coefficient from the aggregate to the concrete, $\beta_{\max }=2 f_{a} /\left(1+f_{a}\right)=0.797$ - i.e. using Eq. (11). Assuming that the average temperature during the irradiation experiments was $250{ }^{\circ} \mathrm{C}$ and that the room temperature was around $20{ }^{\circ} \mathrm{C}$, that the thermal expansion of serpentine remained equal to $7.5 \times 10^{-6}$ per ${ }^{\circ} \mathrm{C}$, and that the thermal expansion of the aggregate lead to irreversible deformation in the matrix, the residual deformation of concrete at " 0 -fluence" is $\beta_{\max } \alpha_{a} \Delta T=0.797 \times 7.5 \times 10^{-6} \times 230=0.137 \%$, which is a value that is close to the linear coefficient obtained by the linear analysis, suggesting the importance of the thermal effects on the residual dimensional change. This simplified analysis does not account for the effect of the dimensional change in the concrete paste. Estimating the expansion transfer 
coefficient from the paste to the concrete as $1-\beta_{\max }=0.203$, the shrinkage of the paste should have reduced the concrete length change by $-0.02 \%$ to $-0.12 \%$, accounting for the scattering of the experimental data. An additional thermal expansion term should also be added. It is of the order of $\left(1-\beta_{\max }\right) \alpha_{m} \Delta T \approx 0.203 \times 9.0 \times 10^{-6} \times 230=0.04 \%$, which is negligible compared to the other sources of permanent deformations. Hence, the shrinkage of the paste should compensate to some extent for the effect of the thermal expansion of the aggregate. In other words, the data points should lie between the two solid lines defined by the equations $\varepsilon_{c}=0.84 \varepsilon_{a}$ and $\varepsilon_{c}=0.84 \varepsilon_{a}+0.13 \%$. A significant number of data points are located above the theoretical upper limit determined by the analysis developed above. Two hypotheses can be formulated to account for that effect: (1) the measurements of the dimensional change of a severely cracked material may lead to significant errors, and (2), the presence of cracking and large deformations cannot be fully modeled with the small perturbation hypothesis used as the basis for this micromechanical theory. Another important question relates to the actual role of the paste shrinkage in the overall dimensional change of the irradiated concrete for the specific experiment of Elleuch et al. (1972). Finding an answer to that question requires to estimate the kinetics of the shrinkage during the irradiation experiment in relation to the kinetics of expansion of the aggregate and the produced damage. The temperature rise occured almost instantaneously at the beginning of the irradiation test, possibly increasing the pre-existing damage in the paste from the pre-drying. Hence, the contraction of the cracked paste induced by drying shrinkage might result in a widening of the pre-existing cracks but not necessarily in a 
significant volumetric change. On the opposite, aggregate thermal expansion is transfered to the concrete almost immediately after the beginning of the irradiation experiment.

Figure 5 compares the actual post-irradiation length change measured on serpentine samples and the estimated dimensional change of serpentine by micromechanical inverse modeling. The input data for the model are the following characteristics measured after the irradiation tests: the residual expansion of the concrete $\varepsilon_{c}$; the residual shrinkage of the pure cement pastes $\varepsilon_{m}$; the pulse wave velocities, respectively $v_{c}$ and $v_{a}$ of concrete and serpentine aggregate; and the estimated temperature $T$. The elastic properties of concrete and aggregate are derived from their respective pulse velocities assuming a Poisson ratio of 0.2 and a constant density, i.e., using Eq. (17). The pulse velocities are calculated using the linear regressions given in Fig. 2. The elastic properties of the cement paste forming the concrete matrix are derived assuming Eq. (1) and (2) and finding the matching value of the effective Poisson ratio in the damaged paste, i.e., using equations (4) and (5). The dimensional change of serpentine is finally estimated after the calculation of effective expansion transfer coefficient [Eq. (9)] and the total free length change of concrete [Eq. (16] and of the cement paste [Eq. (14)]. Both theoretical and measured expansion exhibit important scattering, particularly for fluences beyond $\approx 9.0 \times 10^{19} \mathrm{n} / \mathrm{cm}^{2}$. Data points become more scarce when the fluence exceeds $\approx 2.0 \times 10^{19} \mathrm{n} / \mathrm{cm}^{2}$. For fluence above $\approx 2.0 \times 10^{19} \mathrm{n} / \mathrm{cm}^{2}$, the model tends to overestimate the measured swelling. This observation is consistent with Fig. 4 in which a significant number of concrete swelling data exceed the theoretical bound generated by assuming full damage in the paste 
and maximum thermal expansion of the aggregate. For the sake of providing a more quantitative comparison, the results are fitted with the expansion equation suggested by Zubov and Ivanov (1966) for quartz:

$$
\varepsilon_{a}=\frac{\Delta V}{3 V_{0}}=\frac{\kappa \varepsilon_{\max }\left(e^{\delta \cdot n}-1\right)}{\varepsilon_{\max }+\kappa e^{\delta \cdot n}}
$$

With $\varepsilon_{\max }$ the maximum expansion, $\kappa$ (a dimensionless parameter) and $\delta$ (the inverse of a fluence) govern the shape of the sigmoid. The maximum gap between the two theoretical fitting curves is equal to $0.11 \%$ at a fluence $\approx 7.1 \times 10^{19} \mathrm{n} / \mathrm{cm}^{2}$. The theoretical model based on the homogenization theory of random media captures the predominant role of the aggregate for the description of the RIVE of concrete.

\subsection{Summary}

Based on the above analysis, the following interpretation of the experiment conducted by Elleuch et al. can be proposed: (1) The damage mechanism in serpentine causing a loss of mechanical properties and swelling results only from the neutron irradiation and not from thermal effect. (2) Important damage in the cement paste in concrete is produced initially by the preheating at $250^{\circ} \mathrm{C}$ and is aggravated by the thermal and irradiation-induced swelling of serpentine aggregate. (3) No significant effect of neutron or gamma irradiation on pre-dried cement paste can be inferred. Hence, including a pre-drying phase in the experimental protocol plays an important role in the damage mechanism. It must be emphasized that these conditions are not representative of the actual conditions in commercial reactors: the temperature should be maintained under $65{ }^{\circ} \mathrm{C}$ in most locations, and the moisture content should result from the gradual evaporation of the free water only. 
However, the experiment by Elleuch et al. (1972) provides a consistent and systematic study of the effects of irradiation on the constituents of concrete that is extremely valuable for the validation of the proposed micromechanical model. It also shows the pathway for possible future experimental research.

\section{Experiments Conducted by Kelly et al. (1969)}

Kelly et al. conducted irradiation experiments on concrete; flint and limestone aggregate; and ordinary Portland cement paste; the same data were also published in (Gray, 1971). Aggregates of other natures were also irradiated, but no concrete specimens were prepared with them. The concrete is described as high performance because of its relatively low water-to-cement ratio $(w / c=0.36)$. The use of an admixture such as a plasticizer is not reported. The cement-to-aggregate ratio by weight is $c / a=1: 2.7$. The corresponding aggregate volume fraction is about 0.6. After curing under water, the concrete cylinders were sawed to obtain disks of $2.5 \mathrm{in}$. in diameter and 0.5 in. thick. The unsealed cut specimens were stored in wooden boxes at $20{ }^{\circ} \mathrm{C}$. The irradiation tests were conducted for periods that varied from 1 to 40 days, to obtain a range of neutron fluence between about $1.0 \times 10^{18} \mathrm{n} / \mathrm{cm}^{2}$ and $4.0 \times 10^{19} \mathrm{n} / \mathrm{cm}^{2}$. The temperature during irradiation was $45^{\circ} \mathrm{C} \pm$ $5{ }^{\circ} \mathrm{C}$. Post-irradiation measurements included loss of weight, dimensional change, elastic modulus (resonance frequency), tensile strength and thermal conductivity. In the following section, the results of the experiment by Kelly et al. are examined using the same methodology that was used to evaluate the results of the experiment by Elleuch et al. in Sect. 4.1. 


\subsection{Limestone Aggregate}

\subsubsection{Dynamic Elastic Modulus}

Fig. 6 shows the evolution of the dynamic modulus with the neutron fluence between $1.0 \times 10^{19} \mathrm{n} / \mathrm{cm}^{2}$ and $3.0 \times 10^{19} \mathrm{n} / \mathrm{cm}^{2}$. As limited data are available, prudent interpretation is necessary. A minor reduction of the dynamic modulus is observed for the pure cement paste sample, while limestone samples exhibit a considerable drop: At about $2.5 \times 10^{19} \mathrm{n} / \mathrm{cm}^{2}$, the limestone modulus equals only a third of its initial value and is almost equivalent to that of the pure cement paste. Data published later show that the observed trend is close to the lower envelope of the elastic modulus decrease with the neutron fluence (Gray, 1971, Fig 12.B.) including Kelly et al. (1969)'s data; (Seeberger and Hilsdorf, 1982).

The dynamic modulus of concrete decreases at a much lower rate than that of limestone. Unexpectedly, beyond $\approx 2.0 \times 10^{19} \mathrm{n} / \mathrm{cm}^{2}$, the dynamic modulus of concrete exceeds that of the pure cement paste and the limestone specimens, suggesting the possibility that the pure cement paste samples were not representative of the actual paste in the concrete samples. The waterto-cement ratio of pure paste is not reported, but the density of the pure paste (1.87) is consistent with a water-to-cement ratio of 0.36 and a chemical shrinkage ${ }^{1}$ of about $7 \%$ (value consistent with (Tazawa et al., 1995)). The absorption coefficient of limestone aggregate $(0.78 \%)$ may also have resulted in post-curing prolonged hydration and hardening of concrete samples.

\footnotetext{
${ }^{1}$ The density of the cement paste equals $\rho_{m}=\left(1-\varepsilon_{c s}\right) \rho_{w} \frac{1+w / c}{\rho_{w} / \rho_{c}+w / c}$, where $\varepsilon_{c s}$ designates the chemical shrinkage.
} 
This assumption could not be verified. From a theoretical point of view, the elastic bulk and shear moduli of a perfectly bonded two-phase composite are strictly bounded by those of its constituents. The irradiation-damage scenario suggested in the following results from that assumption. The possibility of differential-expansion early damaged of the aggregate-paste interface causing a debonding could not be explored by the proposed micromechanical model. Hence, the calculation of the crack density in the sense of Budiansky and O'Connell was not possible for the lower values of the aggregate modulus. In Fig. 7, these biased estimations are reported as zero crack density. The crack density of pure paste specimens increases slightly with the irradiation fluence but remains very low $(\zeta \approx 0.05)$. Because the temperature is kept at a low level (i.e., $45^{\circ} \mathrm{C}$ ), no change is expected in the microstructure of cement silicate hydrate (stability of low density C-S-H under $60^{\circ} \mathrm{C}$ ) (Jennings et al., 2007). However, the relative humidity condition during the irradiation test is not reported in the original paper, hence, possible effects on the hydrates microstructure may have occurred. In the following, the loss of weight data is used to evaluate the shrinkage occurring in the cement paste.

\subsubsection{Dimensional Change}

Figure 8 shows the correlation between the expansion of concrete and limestone aggregate at similar fluence levels. While most of the plots obtained using Elleuch et al.'s data showed a correlation between the aggregate swelling and the concrete swelling that was close to the theoretical estimation assuming a fully damaged cement paste, most of Kelly et al.'s data points are located below that theoretical "upper" bound. In some cases, the residual deformation of concrete even exhibits contraction. No immediate correlation 
between the aggregate expansion and the concrete dimensional change can be observed. Following the conclusions from the previous section, the concrete paste irradiation damage is assumed to be low $\left(\zeta_{m} \approx 0.05\right)$. The evolution of the swelling transfer coefficient simply results from that of the damaged bulk modulus of limestone aggregate. Its lower value when the elastic properties of the limestone approach those of the paste tends to be equal to the volume fraction of aggregate $\left(\lim _{k_{a}(n) \rightarrow k_{m}^{0}} \beta=f_{a}\right)$. The thermal expansion of the paste and the aggregate is small $\left(\leq \approx 10^{-5} \times 25=0.025 \%\right)$ and largely reversible. Hence, it is neglected. The deformation of the concrete paste is essentially the result of weight loss-induced shrinkage. The weight loss of limestone concrete increases with the neutron fluence; from $1.0 \%$ to about $2.3 \%$ at $3.0 \times 10^{19} \mathrm{n} / \mathrm{cm}^{2}$. Note that there is no data point between about $5.0 \times 10^{18} \mathrm{n} / \mathrm{cm}^{2}$ and $2.0 \times 10^{19} \mathrm{n} / \mathrm{cm}^{2}$. For pure cement paste samples, there is an almost perfect linear correlation between the dimensional change and the weight loss. Best linear fit gives: $\varepsilon_{m}=-0.191 \Delta m / m_{0}-0.092$, where the paste shrinkage $\varepsilon_{m}$ and the weight loss $\Delta m / m_{0}$ are given in percent. The weight loss of concrete results from the drying of the cement paste and potentially from the release of the absorbed water from aggregate (absorption coefficient $0.78 \%$ ). The total relative weight loss of concrete can be written:

$$
\underbrace{\left.\frac{\Delta m}{m_{0}}\right|_{c}}_{\text {concrete }}=\underbrace{\left.\frac{1}{1+\frac{\rho_{m}}{\rho_{a}} \frac{f_{a}}{1-f_{a}}} \frac{\Delta m}{m_{0}}\right|_{m}}_{\text {cement paste }}+\underbrace{\left.\frac{1}{1+\frac{\rho_{a}}{\rho_{m}} \frac{1-f_{a}}{f_{a}}} \frac{\Delta m}{m_{0}}\right|_{a}}_{\text {aggregate }},
$$

Where $\rho_{m}$ and $\rho_{a}$ are, respectively, the density of the cement paste and the aggregate. Equation (19) can be inversed to determine the actual weight loss in the concrete paste. Assuming a concrete weight loss between $1.0 \%$ and about $2.3 \%$ and accounting for (or not) the possible water absorption in 
aggregate, the actual weight loss of concrete paste is bounded between $1.70 \%$ and $4.84 \%$, and hence, the corresponding shrinkage $\varepsilon_{m}$ between $-0.416 \%$ and $-1.016 \%$. Figure 9 shows the measured and the theoretically estimated aggregate expansion with the fast neutron fluence. The expansion curve, both in amplitude and kinetics, is correctly reproduced. The sudden step-like increase of the limestone swelling around $2.5 \times 10^{19} \mathrm{n} / \mathrm{cm}^{2}$ observed during the experiment is confirmed by the inverse homogenization. No other concrete characteristics (strength, modulus, thermal resistance) exhibit similar behavior.

\subsection{Flint Aggregate}

Flint is sedimentary cryptocrystalline form of quartz categorized as a variety of dense black or grey chert.

\subsubsection{Dynamic Elastic Modulus}

The evolution of the Young's modulus of irradiated flint concrete is not reported in Kelly et al.'s, or later in Gray, and the number of data points provided for flint aggregate are far from being sufficient to derive an accurate trending (see Fig. 10). The pure cement data are the same as those presented in the limestone aggregate section. Flint Young's modulus exhibits a sharp drop of about half of its initial value at $\approx 2.0 \times 10^{19} \mathrm{n} / \mathrm{cm}^{2}$. No other data are available.

\subsubsection{Dimensional Change}

Figure 11 (flint aggregate swelling against flint concrete swelling) shows that the measured concrete length change is significantly higher than that of flint aggregate. The best linear fit coefficient is close to 2 (i.e., the concrete 
swelling is about twice as large as that of the flint), while the regression coefficients were found to be equal to 0.84 and 0.33 , respectively, for serpentine and limestone aggregate (see Figs. 4 and 8). The reported maximum expansion reported by Kelly et al. (1969) is about 4.5\%; it was only about $1.5 \%$ for flint aggregate and $0.7 \%$ for serpentine. Seeberger and Hilsdorf (1982) measured expansion generally below $1 \%$ on most tested concrete, except for concrete specimens made with granite, which exhibited large length change of about 5 to $8 \%$ at $1.0 \times 10^{19} \mathrm{n} / \mathrm{cm}^{2}$ fluence. These specimens were reported as destroyed before reaching $5.0 \times 10^{19} \mathrm{n} / \mathrm{cm}^{2}$ fluence. Note that the strain at rupture under uniaxial tension loading measured on a granite sample was about $0.7 \%$ at an unreported fluence, doubling the ductility of the non-irradiated rock.

From a theoretical perspective, the proposed model, which is based on small strain linear theory, cannot explain the large deformations observed on concrete made of flint aggregate as the expansion transfer coefficient $\beta$ is bounded at 1 by definition. If no important thermal-induced swelling occurs (see, for example, the interpretation of Elleuch et al.'s data), obtaining volumetric expansion significantly higher for concrete than for aggregate should suggest extensive cracking associated with important loss of cohesion between the paste and aggregate. This hypothesis is supported to some extent by the observed loss of strength: The flint concrete lost about twothirds of its initial tensile strength at $\approx 3.0 \times 10^{19} \mathrm{n} / \mathrm{cm}^{2}$ fluence, whereas the limestone concrete only lost half of its initial tensile strength. However, the paste-aggregate loss of cohesion-induced large deformation hypothesis seems inadequate to describe why, even for rather the small expansion of 
flint aggregate below $0.3 \%$, the expansion of the corresponding concrete is much larger. This observation is quite inconsistent with the others results from Kelly et al. on limestone concrete and Elleuch et al. on serpentine concrete. In the extensive review of literature data presented in our companion paper, Kelly et al.'s measurements of expansions of flint aggregate exhibit a singular behavior out of the bounds of the $95 \%$ prediction interval based on a nucleation growth model. A speculative hypothesis (unfortunately impossible to assess on 45-year old data) assumes that the reported "growth" for flint aggregate was volumetric swelling and not length change. Interestingly, that hypothesis leads to a close agreement between the measured and modeled swelling of flint at various irradiation fluences [see Fig. 12] and resolves the anomalous behavior. The impossibility of assessing either of the two hypotheses formulated illustrates the need to reproduce similar experiments to confirm or infirm whether flint aggregates exhibit a singular behavior similar to that observed by Kelly et al..

\subsection{Summary}

Kelly et al.'s experiments offer a perspective that differs from the experiment of Elleuch et al.. The materials used and the temperature during irradiation are more representative of structural concrete for existing shield buildings/RPV supports. Once again, no significant impact of neutron irradiation on mechanical properties (elasticity, tensile strength) of cement paste was observed. Although numerous aggregate types have been tested, only two concrete mixes were formulated: one with limestone aggregate and the other with flint aggregate. Interestingly, these two concretes exhibited two singularly different behaviors: (1) Limestone concrete: No significant 
damage seems to have occurred in the concrete paste. This phenomenon is attributed to the quick drop of elastic properties of the limestone with increasing irradiation. Rapidly, the limestone Young's modulus becomes close to that of the cement paste. Hence, aggregate expansion or cement paste shrinkage occur almost freely in the concrete. The loss of strength in the limestone concrete is attributed to the aggregate damage. Since the paste is almost intact, it is likely that the concrete failure occurs by cross-aggregate fracturing. (2) Flint concrete: No elastic properties were reported by the authors for concrete. As a result, the theoretical analysis was incomplete and is subject to uncertainties. It seems that the concrete cement paste experienced important damage during the irradiation tests as the result of the aggregate expansion since no specific pre-irradiation thermal treatment, but free drying, was applied (storage in an open wooden box at $20^{\circ} \mathrm{C}$ ). Much larger expansion is reported on concrete than on flint aggregate at similar fluence.

\section{Discussion}

\subsection{Simplified Estimation of Radiation-Induced Volumetric Expansion of Concrete}

The RIVE of concrete depends primarily on three variables: the radiationinduced aggregate expansion, the cement paste shrinkage and, potentially, the aggregate thermal expansion. The material parameter connecting these three inputs to concrete swelling is the expansion transfer coefficient $\beta$ that is a function of the elastic properties of the damaged aggregate and the cracked paste. Based on the studied experimental data, two "bounding" situations 
were observed: (1) important cracking of the cement paste with progressive degradation of the aggregate $\left(k_{a}>>\tilde{k}_{m}\right)$ and (2) important neutron damage in the aggregate that decreases its elastic bulk modulus to a value that is comparable to that of the paste, the latter not being significantly affected by cracking $\left(k_{a} \approx k_{m}\right)$. Assuming Eq. (10) as a close solution for $\beta$ makes it possible to derive approximations for the two situations described previously (i.e., $\beta^{(i)}=2 f_{a} /\left(1+f_{a}\right)$ or $\left.\beta^{(i i)}=f_{a}\right)$. These expressions are advantageously independent of the elastic properties of the damaged constituting materials and are only functions of the aggregate volume fraction. In the absence of accurate data, the maximum paste shrinkage is expected to be around $\hat{\varepsilon}_{m}^{s h} \approx$ $0.5 \%$. Knowing the temperature $T$ during irradiation leads to the thermal expansion that can be calculated assuming a thermal expansion coefficient of about $\hat{\alpha} \approx 10^{-5}{ }^{\circ} \mathrm{C}^{-1}$ at a reference temperature of $20^{\circ} \mathrm{C}\left(\Delta T=T-20{ }^{\circ} \mathrm{C}\right)$. Important discrepancies are observed between different aggregates in terms of RIVE amplitude and kinetics. Further research is needed to isolate the behavior to the constitutive minerals and then reconstruct the homogenized expansion of aggregate. Presently, the aggregate swelling $\hat{\varepsilon}_{a}(n)$ is modeled by Zubov and Ivanov's expression [Eq. (18)]. The best fit parameters are given for each type of aggregate studied by Kelly et al. and by Elleuch et al. in Fig. 13 (Left plots). Two bounding estimations of the concrete expansion are calculated:

$$
\hat{\varepsilon}_{c}^{(i)}=\frac{2 f_{a}}{1+f_{a}}\left(\hat{\varepsilon}_{a}(n)+\hat{\alpha} \Delta T\right) \text { and } \hat{\varepsilon}_{c}^{(i i)}=f_{a} \hat{\varepsilon}_{a}(n)+\left(1-f_{a}\right) \hat{\varepsilon}_{m}^{s h}
$$

Both expressions are plotted in Fig. 13 (Right). Most experimental data are captured between the two calculated curves. 


\subsection{Gamma Ray Effects}

The possible effects of gamma ray on the mechanical properties of cement paste could not be assessed from the experiments conducted by Kelly et al. and Elleuch et al.. In both cases, no significant change on the cement paste mechanical properties could be observed although the estimated maximum gamma doses were high. Kelly et al. also conducted a gamma-irradiation experiment at a dose rate of about $5.0 \mathrm{kGy} / \mathrm{h}$ on two concretes, one being the limestone concrete to total doses of 227 and 470 MGy. It is unclear whether the observed loss of elastic and tensile properties of about $10 \%$ was caused by one or more of the following mechanisms: "natural" drying (including gamma heating), radiolysis-induced accelerated drying (since large gas releases were observed), radiolysis-induced carbonation, or, more generally, degradation of the calcium-bearing cement hydrates. It is worth noting that for about the same loss of weight, the tensile strength of the gamma-irradiated specimen is reduced by only about $10 \%$, while the neutron-irradiated sample lost half of its initial tensile strength. Without negating possible interactions with gamma rays, data generated by Kelly et al. and Elleuch et al. emphasize the predominant role of the aggregate in the development of neutron irradiationinduced swelling and the potential creation or aggravation of damage in the surrounding paste. The interpretation based on the micromechanical approach pursued herein fully aligns with those observations.

\subsection{Implications for Biological Shield and Reactor Pressure Vessel Support Structures}

The dose rate in a test reactor is higher by two to three orders of magnitude than the estimated average dose rate in a pressurized water reactor. 
First, it is questionable how dose rate affects silicate-based minerals. Further research is needed to answer this question. Second, the aggregate "fastswelling" can produce higher induced microcracking in the concrete paste because of the limited time allowed for stress relaxation (Nguyen et al., 2010). Time-dependent deformations, i.e., shrinkage and creep, in cementitious materials are primarily dependent on the internal water content. Small sized samples used for obvious reasons in test reactors cause faster water evaporation interacting with shrinkage, creep and stress relaxation in the cement paste. Natural moisture transport in the biological shield or RPV support structures will occur at a much slower rate. The effect of radiolysis-induced gas release on the transport kinetics certainly requires more studies. Hence, transposition of the accelerated experimental data to operating condition cannot only rely on the neutron or gamma fluence; There must also be a clear understanding of the temperature and internal humidity evolution in the studied structure. Another consequence of the moisture transport kinetics is the evolution of the paste contraction (shrinkage).

The mechanical behavior of the biological shield will result from temperature, moisture, fluence, and, possibly, gamma dose profiles from the wall surface in the reactor cavity to the inside of the structure. Assuming a rapid decay of the fast neutron fluence with the penetration depth in concrete (one order of magnitude can be lost within the first 10-20 cm), the RIVE will be much higher near the surface and will vanish towards the bulk of the structures. The resulting differential induced swelling and possibly the differential paste shrinkage will cause the development of stresses near the surface of the biological shield. The structural significance of the restrained 
deformation will depend on the amplitude and the kinetics of the aggregate swelling and paste shrinkage. Such analysis can be performed in the spirit of the work of Pomaro et al. (2011) based on finite element analysis. Although Pomaro et al.'s numerical simulations are certainly the first solid computational work trying to develop a radiation-damage model coupled with temperature and moisture transport, note that (1) the damage model was based, because of lack of better data, on the lowest envelope curve derived from Hilsdorf et al. (1978)'s data collection with all the limitations discussed in Kontani et al. (2010)'s paper and in our companion paper, and that (2) the authors did not account for the RIVE in their constitutive law. Enhanced numerical simulations will be possible when there are better data available about radiation-induced swelling and damaged mechanical properties either obtained by further testing or derived by micromechanical modeling such as presented herein.

\section{Conclusions}

RIVE may result in important deformations, that are comparable in amplitude, or potentially higher, than alkali-silica reaction-induced expansion. Neutron fluence attenuation with depth in the concrete biological shield will cause RIVE gradient (constrained expansion). Effects of restrained RIVE-

induced stresses on potential structural damage must be the subject of future research.

A micromechanical model for concrete subjected to neutron irradiation has been developed. A comparison with limited published experimental data highlights the importance of separating the irradiation effects in the aggre- 
gate and in the cement paste and understanding their interaction. The predominant role of the aggregate on damage and swelling is confirmed and quantified. Pre-existing damage in the cement paste is clearly aggravated by the aggregate expansion though the reduction of the elastic properties of the aggregate tends to reduce the expansion transfer to the paste.

Of the extensive literature review conducted and presented in our companion paper, only the data published by Kelly et al. (1969) and Elleuch et al. (1972) contains systematic information with pre- and post-irradiation characterization of the cement paste, the aggregate and concrete made of the previous two constituents. The mechanistic understanding of irradiation effects in concrete needs further experimental investigation in that spirit.

The broad classification of aggregate (i.e., limestone, silicate and miscellaneous/trap) used in our companion paper (Field et al., 2014) provided a qualitative partitioning that led to the identification of the radiation-induced volumetric expansion, resulting primarily from silicate-based mineral amorphization. For quantitive analysis, this general classification might be inappropriate because different mineral compositions can affect an aggregate's susceptibility to neutron radiation damage.

The inherent limitations of the proposed modeling, which is based on the theory of homogenization of random media, must be overcome. In particular, the behavior of concrete during an irradiation test results from the combined effects of several mechanisms, including neutron damage, gamma radiolysis, and moisture transport coupled with thermal effects. The incremental nature of these mechanisms is not modeled by the linear approach adopted here: These mechanisms need to be included in the modeling because differ- 
ent mechanism kinetics may result in different macroscopic behavior. This work is crucial for valid transposition of accelerated experimental results to operating reactor conditions.

\section{Acknowledgements}

The authors would like to thank Pr. Ippei Maruyama, Dr. D. Naus, Dr. T.M. Rosseel and Dr. J.T. Busby for their thoughtful discussions on the presented topics. This research is sponsored by the DOE Light Water Reactor Sustainability Program. This manuscript has been authored by the Oak Ridge National Laboratory, managed by UT-Battelle LLC under Contract No. DE-AC05-00OR22725 with the U.S. Department of Energy. The publisher, by accepting the article for publication, acknowledges that the U.S. Government retains a nonexclusive, paid-up, irrevocable, worldwide license to publish or reproduce the published form of this manuscript, or allow others to do so, for U.S. Government purposes.

\section{References}

ASTM C294-12, . Standard Descriptive Nomenclature for Constituents of Concrete Aggregates. Committee C09. 100 Barr Harbor Drive, PO Box C700, West Conshohocken, PA 19428-2959, USA.

ASTM C597-09, . Standard Test Method for Pulse Velocity Through Concrete. Committee C09. 100 Barr Harbor Drive, PO Box C700, West Conshohocken, PA 19428-2959, USA.

Bažant, Z., Kaplan, M., 1996. Concrete at high temperatures: materials properties, mathematical models. Longman, London, United Kingdom. 
Ben Haha, M., 2006. Mechanical Effects of Alkali-Silica Reaction in Concrete Studied by SEM-Image Analysis. Ph.D. thesis. Ecole Polytechnique Fédérale de Lausanne.

Benveniste, Y., 1987. A new approach to the application of Mori-Tanaka's theory in composite materials. Mechanics of Materials 6, 147-157.

Bernard, O., Ulm, F., Lemarchand, E., 2003. A multiscale micromechanicshydration model for early age elastic properties of cement based materials. Cement and Concrete Research 33, 1293-1309.

Bonnet, J., Boissier, M., Gherbi, A.A., 1994. The amorphization process of neutron-irradiated crystalline quartz studied by Brillouin scattering. Journal of Non-Crystalline Solids 167, 199-204.

Bouniol, P., 2004. State of knowledge on the water radiolysis in cemented wasteforms and its approach by simulation. Technical Report CEA-R-6069. Commissariat à l'Energie Atomique. CEA / Saclay 91191 Gif-sur-Yvette Cedex France. In French.

Bouniol, P., Aspart, A., 1998. Disappearance of oxygen in concrete under irradiation: the role of peroxides in radiolysis. Cement and Concrete Research $28,1669-1681$.

Browne, R., 1967. Properties of concrete in reactor vessels, in: Proceedings of the Conference on Prestressed Concrete Pressure Vessels, Institute of Civil Engineers, London, UK. pp. 131-151.

Budiansky, B., O'Connell, R., 1976. Elastic moduli of a cracked solid. International Journal of Solids and Structures 12, 81-97. 
Christensen, R., Lo, K., 1979. Solutions for effective shear properties in three-phases sphere and cylinder models. Journal of the Mechanics and Physics of Solids 27, 315-330. Erratum (1986), vol. 34.

Crowley, M., 1956. Initial thermal expansion characteristics of insulating refractory concretes. Bulletin of the American Ceramic Society 35, 465468.

Cruz, C.R., Gillen, M., 1980. Thermal expansion of Portland cement paste, mortar and concrete at high temperatures. Fire and Materials 4, 66-70.

Dormieux, L., Kondo, J., Ulm, F.J. (Eds.), 2006. Microporomechanics. John Wiley and Sons, Ltd, Hoboken, NJ.

Dubrovskii, V., Ibragimov, S., Ladygin, A., Kulakovskii, M., Pergamenshchik, B., 1968. Radiation stability of serpentine concrete. Soviet Atomic Energy 25, 1345-1346.

Dubrovskii, V., Ibragimov, S., Ladygyn, A.Y., Pergamenshchik, B.K., 1966. The effect of neutron irradiation on certain properties of refractory concretes. Atomnaya Energiya 21, 108-112. English Translation.

Elleuch, L., Dubois, F., Rappenau, J., 1971. Behavior of special shielding concretes and of their constituents under neutron irradiation, in: Fourth United Nations International Conference on the Peaceful Uses of Atomic Energy, p. 7.

Elleuch, L., Dubois, F., Rappeneau, J., 1972. Effects of neutron radiation on special concretes and their components. Special Publication of The American Concrete Institute 43, 1071-1108. 
Emanuel, J., Leroy Hulsey, J., 1977. Prediction of the thermal coefficient of expansion of concrete. ACI Journal 74, 149-155.

Eshelby, J., 1957. The determination of the elastic field of an ellipsoidal inclusion and related problems. Proceedings of the Royal Society 241, $376-396$.

Field, K., Remec, I., Le Pape, Y., 2014. Radiation Effects on Concrete for Nuclear Power Plants, Part I: Quantification of Radiation Exposure and Radiation Effects. Nuclear Engineering and Design Under review.

Grattan-Bellew, P., Chan, G., 2013. Comparison of the morphology of alkalisilica gel formed in limestones in concrete affected by the so-called alkalicarbonate reaction (ACR) and alkali-silica reaction (ASR). Cement and Concrete Research 47, $51-54$.

Graves, H., Le Pape, Y., Naus, D., Rashid, J., Saouma, V., Sheikh, A., Wall, J., 2014. Expanded Material Degradation Assessment (EMDA), Volume 4: Aging of Concrete. Technical Report NUREG/CR-7153, ORNL/TM2011/545. U.S. Nuclear Regulatory Commission. Under review.

Gray, B., 1971. The effects of reactor radiation on cement and concrete, in: Proceedings of an Information Exchange Meeting on 'Results of Concrete Irradiation Programmes', Commission des Communautés Européennes, Brussels, Belgium.

Griffith, J., 1936. Thermal expansion of typical american rock. Iowa Engineering Experiments 128(35), 36 p. Iowa State College of Agriculture and Mechanics Arts. 
Hansen, T., 1986. Physical structure of hardened cement paste, a classical approach. Matériaux et Constructions 19, 423-436.

Harada, T., Takeda, T., Yamane, S., Furumura, F., 1972. Strength, elasticity and thermal properties of concrete subjected to elevated temperatures. Concrete for Nuclear Reactors SP-34-21, 377-406.

Harbsmeier, F., Boise, W., 1998. Ion beam induced amorphization in alpha quartz. Journal of Applied Physics 83, 4049-4054.

Hashin, Z., Shtrikman, S., 1963. A variational approach to the theory of the elastic behaviour of multiphase materials. Journal of the Mechanics and Physics of Solids 11, 127-140.

Hershey, A., 1954. The elasticity of isotropic aggregate of anisotropic cubic crystals. Journal of Applied Mechanics 21, 241-249.

Hervé, E., Zaoui, A., 1993. n-Layered inclusion-based micromechanical modelling. International Journal of Engineering Science 31, 1-10.

Hilsdorf, H., Kropp, J., Koch, H., 1978. The effects of nuclear radiation on the mechanical properties of concrete. Special Publication of The American Concrete Institute 55, 223-254.

Hobbs, D., 1969. Bulk modulus shrinkage and thermal expansion of a two phase material. Nature 222, 849-851.

Jennings, H.M., Thomas, J.J., Gevrenov, J.S., Constantinides, G., Ulm, F.J., 2007. A multi-technique investigation of the nanoporosity of cement paste. Cement and Concrete Research 37, 329-336. 
Johnson, W., Parsons, W., 1944. Thermal expansion of concrete aggregate materials. Journal of Research of the National Bureau of Standards 32, $101-126$.

Katayama, T., 2004. How to identify carbonate rock reactions in concrete. Materials Characterization 53, 85-104.

Katayama, T., 2010. The so-called alkali-carbonate reaction (ACR) - its mineral and geochemical details, with special reference to ASR. Cement and Concrete Research 40, 643-675.

Kelly, B., Brocklehurst, J., Mottershead, D., McNearney, S., 1969. The effects of reactor radiation on concrete, in: Proceedings of the Second Information Meeting on Pre Stress Concrete and Reactor Pressure Vessels and their Thermal Isolation, Brussels. pp. 237-265.

Kontani, O., Ichikawa, Y., Ishizawa, A., Takizawa, M., Sato, O., 2010. Irradiation effects on concrete structure, in: International Symposium on the Ageing Management and Maintenance of Nuclear Power Plants, pp. 173-182.

Kontani, O., Sawada, S., Maruyama, I., Takizawa, M., Sato, O., 2013. Evaluation of irradiation effects on concrete structure - gamma ray irradiation tests on cement paste, in: Proceedings of the ASME 2013 Power Conference POWER2013, Boston, MA, USA.

Kröner, E., 1977. Bounds for effective elastic moduli of disordered materials. Journal of the Mechanics and Physics of Solids 24, 137-155. 
Le Pape, Y., Toulemonde, C., Sanahuja, J., Giorla, A., Bary, B., 2009. Upscaling concrete properties: a rational approach to account for the material complexity and variability. International Journal of Materials and Structural Integrity 3, 227-246.

Le Roy, R., 1995. Déformations instantanées et différées des bétons à hautes performances. Ph.D. thesis. Ecole Nationale des Ponts et Chaussées.

Le Roy, R., Granger, L., 1995. Calcul des déformations instantanées et de fluage propre du béton à partir de celle de la pâte de ciment. Bulletin de Liaison du Laboratoire des Ponts et Chaussées 196, 67-78.

Łowińska-Kluge, A., Piszora, P., 2008. Effect of gamma irradiation on cement composite observed with XRD and SEM methods in the range of radiation dose 0-1409 MGy. Acta Physica Polonica 114, 399-411.

Manzano-Santamaría, J., Olivares, J., Rivera, A., Agulló-López, F., 2012. Electronic damage in quartz $\left(\mathrm{c}-\mathrm{SiO}_{2}\right)$ by $\mathrm{MeV}$ ion irradiations: Potentiality for optical waveguiding applications. Nuclear Instruments and Methods in Physics Research Section B: Beam Interactions with Materials and Atoms 272, 271-274. Proceedings of the 17th International Conference on Ion Beam Modification of Materials (IBMM 2010).

Maruyama, I., Kontani, O., Ishizawa, A., Takizawa, M., Sato, O., 2012. Development of system for evaluating concrete strength deterioration due to radiation and resultant heat, in: 3rd International Conference on NPP Life Management for Long Term Operations, Salt Lake City, USA. 
Mehta, P., Monteiro, P., 2006. Concrete - Microstruture, Properties and Materials. McGraw-Hill, New York.

Mori, T., Tanaka, K., 1973. Average stress in matrix and average elastic energy of materials with misfitting inclusions. Acta Metallica 21, 571-574.

Naus, D., 2005. The Effect of Elevated Temperature on Concrete Materials and Structures - A Literature Review. Technical Report ORNL/TM2005/553. Oak Ridge National Laboratory. Oak Ridge, TN.

Naus, D., 2010. A Compilation of Elevated Temperature Concrete Material Property Data and Information for Use in Assessments of Nuclear Power Plant Reinforced Concrete Structures. Technical Report NUREG/CR7031, ORNL/TM-2009/175. Oak Ridge National Laboratory.

Nguyen, S.T., Dormieux, L., Le Pape, Y., Sanahuja, J., 2010. Crack propagation in viscoelastic structures: Theoretical and numerical analyses. Computational Materials Science 50, 83-91. doi:10.1016/j.commatsci.2010.07.010.

Noumowé, N.A., 1995. Effet de hautes températures $\left(20^{\circ} \mathrm{C}-600^{\circ} \mathrm{C}\right)$ sur le béton. Cas particulier du BHP. Ph.D. thesis. Institut National des Sciences Appliquées.

Philleo, R., 1958. Some Physical Properties of Concrete at High Temperature. Technical Report Research Department Bulletin 97. Portland Cement Association. Skokie, IL.

Pichler, C., Lackner, R., Mang, H., 2007. A multiscale micromechanics model 
for the autogenous-shrinkage deformation of early-age cement-based materials. Engineering Fracture Mechanics 74, 34-58.

Pihlajavaara, S., 1974. A review of some of the main results of a research on the ageing phenomena of concrete: Effect of moisture conditions on strength, shrinkage and creep of mature concrete. Cement and Concrete Research 4, 761-771.

Pomaro, B., Salomoni, V., Gramegna, F., Prete, G., Majorana, C., 2011. Radiation damage evaluation on concrete within a facility for selective production of exotic species (SPES Project), Italy. Journal of Hazardous Materials 194, 169-177.

Powers, T., Brownyard, T., 1948. Studies of the physical properties of hardened cement paste. Technical Report. Research Laboratories of the Portland Cement Association. Chicago.

Sanahuja, J., Dormieux, L., Chanvillard, G., 2007. Modelling elasticity of a hydrating cement paste. Cement and Concrete Research 37, 1427-1439.

Seeberger, J., Hilsdorf, H., 1982. Einfluß von radioactiver Strahlung auf die Festogkeit and Struktur von Beton. Technical Report NR 2505. Institut für Massivbau and Baustofftechnologie, Universität Karlsruhe.

Tazawa, E., Miyazawa, S., Kasai, T., 1995. Chemical shrinkage and autogenous shrinkage of hydrating cement paste. Cement and Concrete Research 25, 288-292.

Vodák, F., Trtik, K., Sopko, V., Kapičková, O., Demo, P., 2005. Effect of 
$\gamma$-irradiation on strength of concrete for nuclear-safety structures. Cement and Concrete Research 35, 1447-1451.

Vodák, F., Vydra, V., Trtik, K., Kapičková, O., 2010. Effect of gamma irradiation on hardened cement paste, in: Proceedings of the Second International Conference on Sustainable Construction Materials and Technologies, Universita Politecnica delle Marche, Ancona, Italy.

Vodák, F., Vydra, V., Trtik, K., Kapičková, O., 2011. Effect of gamma irradiation on properties of hardened cement paste. Materials and Structures 44, 101-107.

Walsh, J., 1965. The effect of cracks on the compressibility of rocks. Journal of Geophysical Research 70, 381-389.

Zubov, V., Ivanov, A., 1966. Expansion of quartz caused by irradiation with fast neutrons. Soviet Physics Crystallography 11, 372-374. 
Figure 1: Homogenization model for concrete under irradiation.

Figure 2: Post-irradiation pulse velocity measured on concrete, pure cement paste and serpentine samples.

Figure 3: Post-irradiation estimated crack density (in the sense of Budiansky and O'Connell (1976)) in the pure cement paste samples and the cement paste in concrete. (Left) Crack density evolution with the received fluence. (Right) Crack density in the pure cement paste against the temperature during irradiation.

Figure 4: Post-irradiation length change. Correlation between the measured expansions of serpentine and concrete samples 
Figure 5: Post-irradiation length change. Comparison between the estimated theoretical length change obtained by inverse homogenization (vertical bars) and the measured postirradiation length change of serpentine (large diamonds). The amplitude of the vertical bars accounts for the scatter band of shrinkage in the cement paste: the filled diamonds are obtained assuming shrinkage of $-0.6 \%$, i.e. the maximum value reported by Elleuch et al. (1972); the empty diamonds assume that the paste shrinkage does not affect the total deformation of the concrete because the shrinkage of the pre-damaged cement paste essentially results in the widening of the existing cracking. Solid lines $(a)$ and $(b)$ correspond to the best fitting curves obtained assuming Zubov and Ivanov (1966)'s expansion model for quartz: $(a)$ is derived from calculated swelling, assuming no effect of paste shrinkage; (b) corresponds to the measured swelling.

Figure 6: Post-irradiation dynamic modulus measured on concrete, pure cement paste and limestone samples.

Figure 7: Post-irradiation estimated crack density (in the sense of Budiansky and O'Connell (1976)) in the pure cement paste samples and the cement paste in concrete. Evolution with the received fluence. The estimated values for the concrete cement paste at about $2.0 \times 10^{19} \mathrm{n} / \mathrm{cm}^{2}$ are biased. See explanation in the Sect. 5.1.1. 
Figure 8: Post irradiation length change. Correlation between the measured expansion of serpentine and that of the concrete samples.

Figure 9: Comparison between the estimated theoretical length change of aggregate and the corresponding measured length change. The vertical lines correspond to the uncertainties related to the actual shrinkage of the cement paste during the irradiation experiments.

Figure 10: Post-irradiation dynamic modulus measured on cement paste and flint samples.

Figure 11: Post-irradiation length change. Correlation between the measured expansion of serpentine and that of the concrete samples. Circles correspond to the original published data (Kelly et al., 1969). Asterisks assume a correction factor on concrete expansion of 3 (see explanation in Sect. 5.2.2.) 
Figure 12: Post-irradiation length change. Comparison between the estimated theoretical length change of aggregate and the corresponding measured length change. The vertical lines correspond to the uncertainties related to the actual shrinkage of the cement paste during the irradiation experiments. Filled diamonds are derived from the original published concrete expansion studies. Empty diamonds are derived after correction of the concrete expansion; an average value for the shrinkage of the paste is assumed.

Figure 13: Post-irradiation length change. (Left column) Measured aggregate expansion (triangle: serpentine, circle: limestone, diamond: flint). The solid lines correspond to the best fitting curve assuming Zubov and Ivanov (1966)'s model (parameters given above the respective plots). The dashed lines assume the same model modifying parameter $\varepsilon_{\max }$ to obtain envelop estimations of the swelling. (Right column) Measured concrete expansions and theoretical estimations, Eq. (20). 


\section{Hashin Composite}

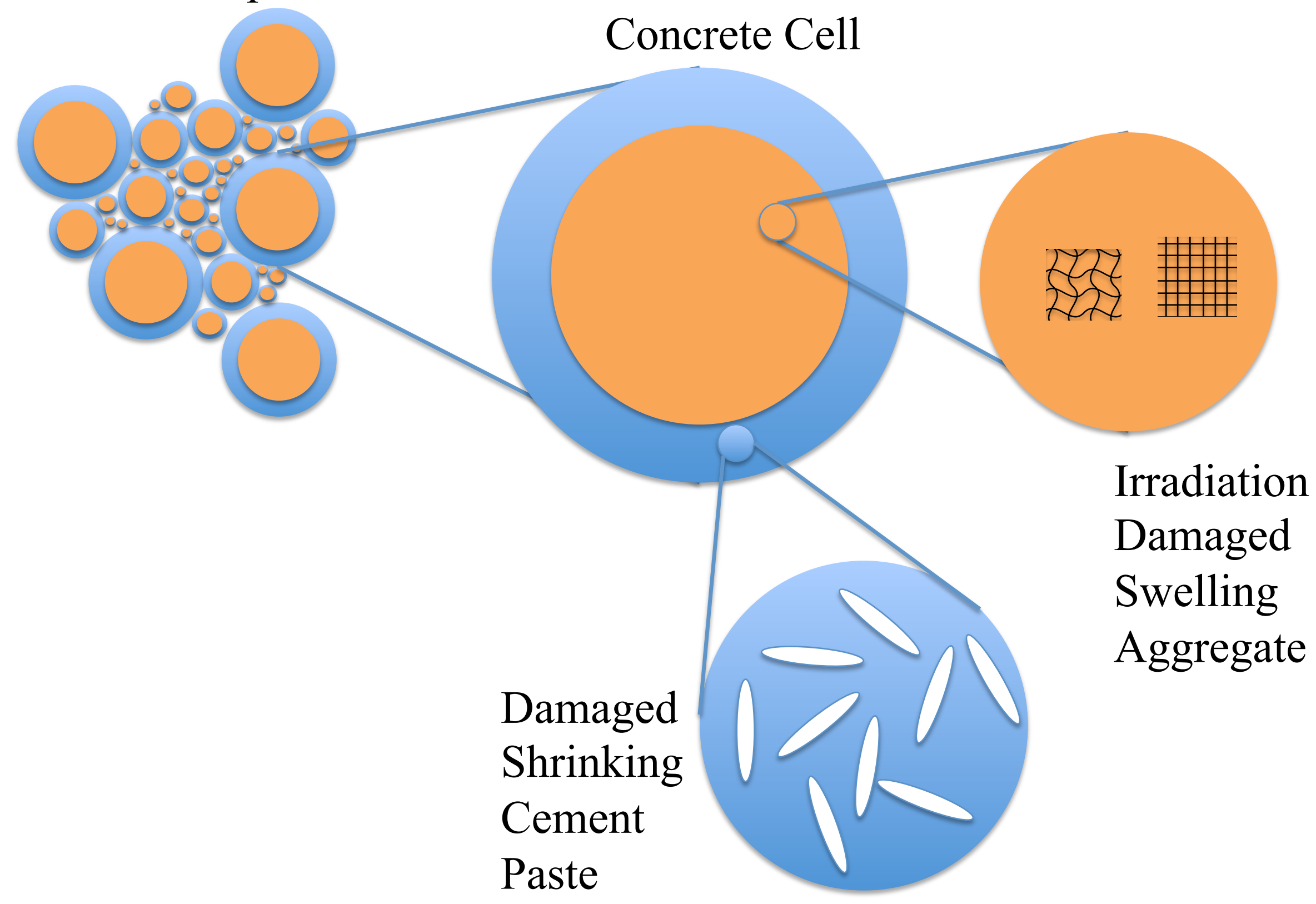




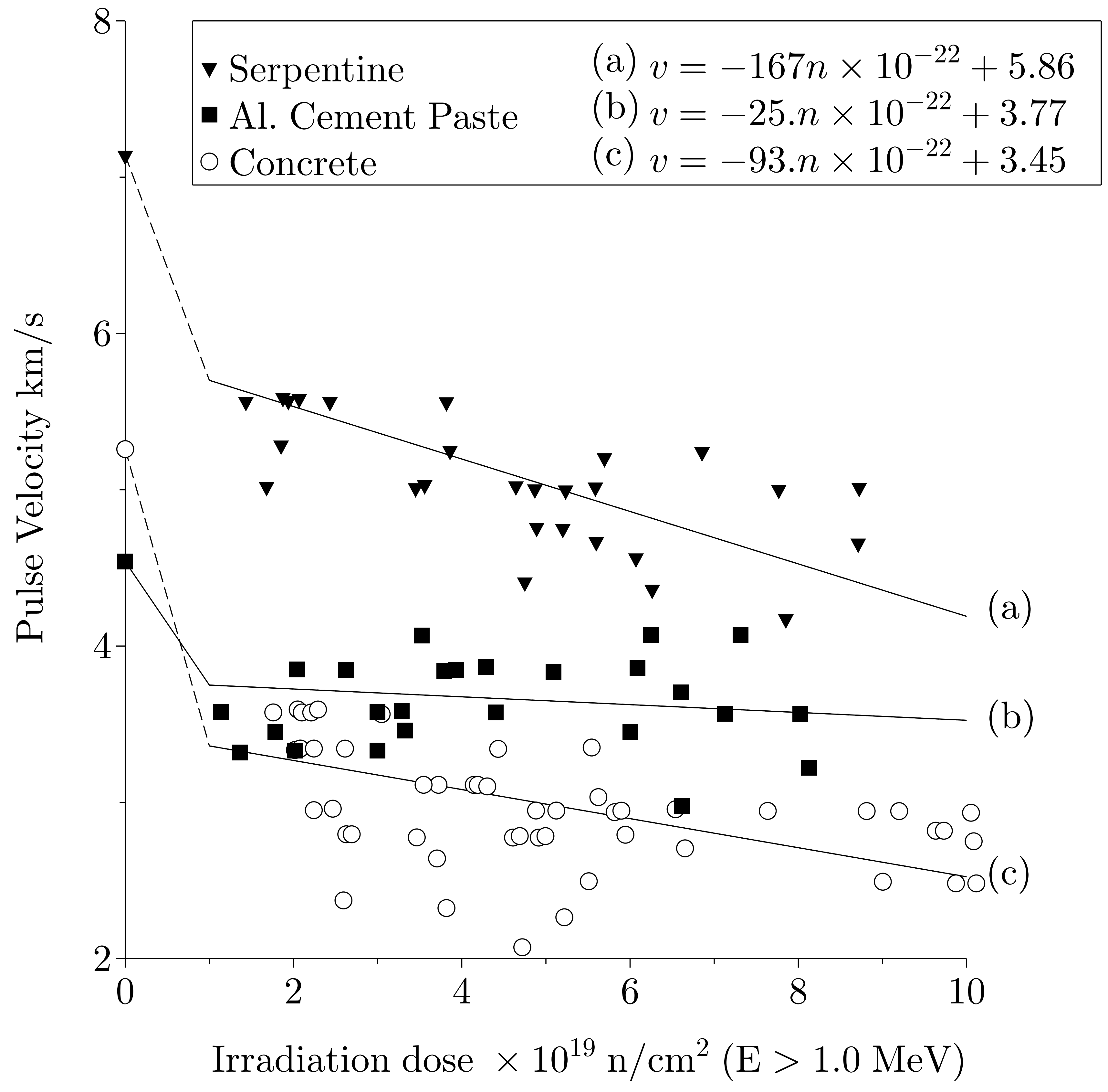



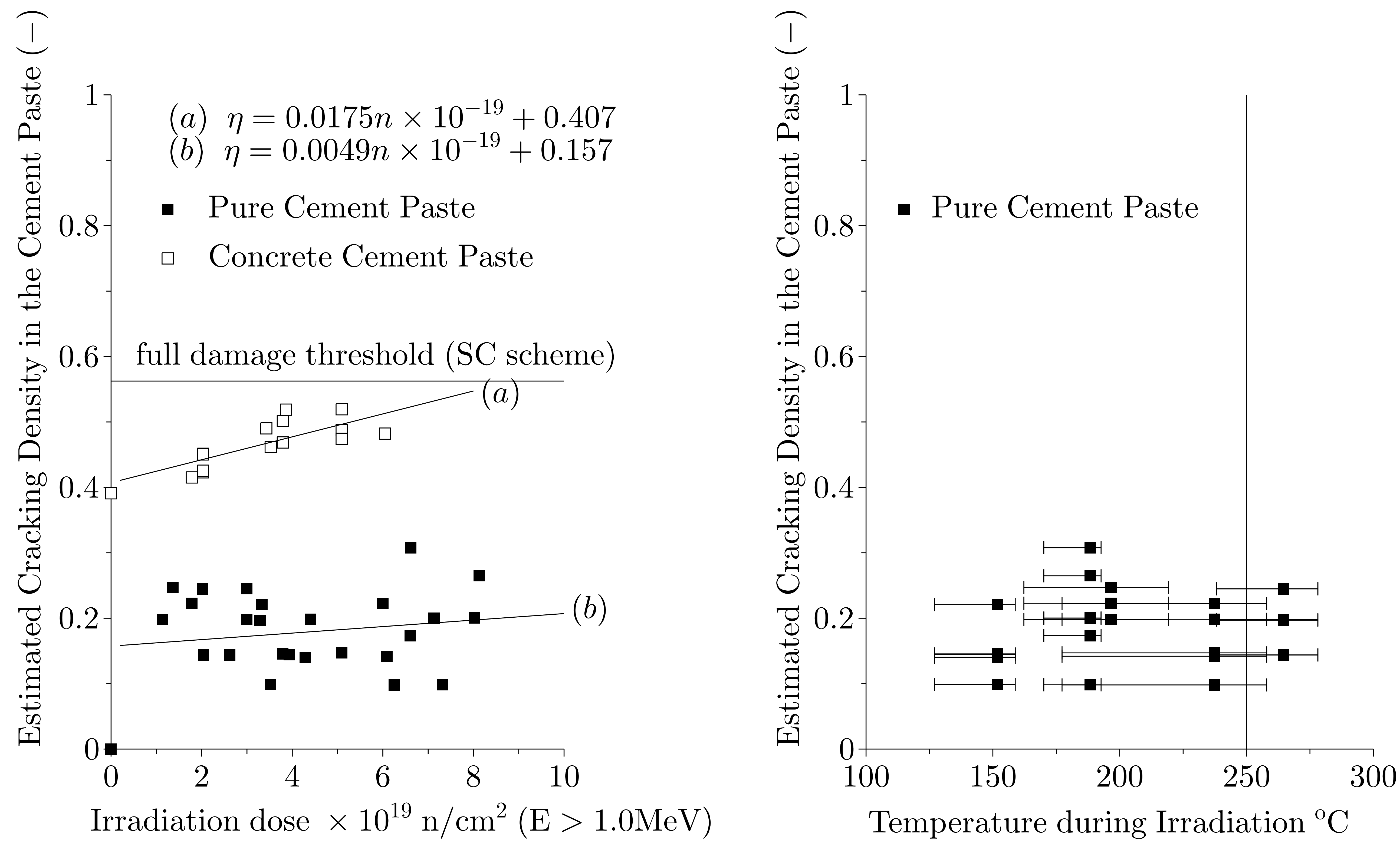


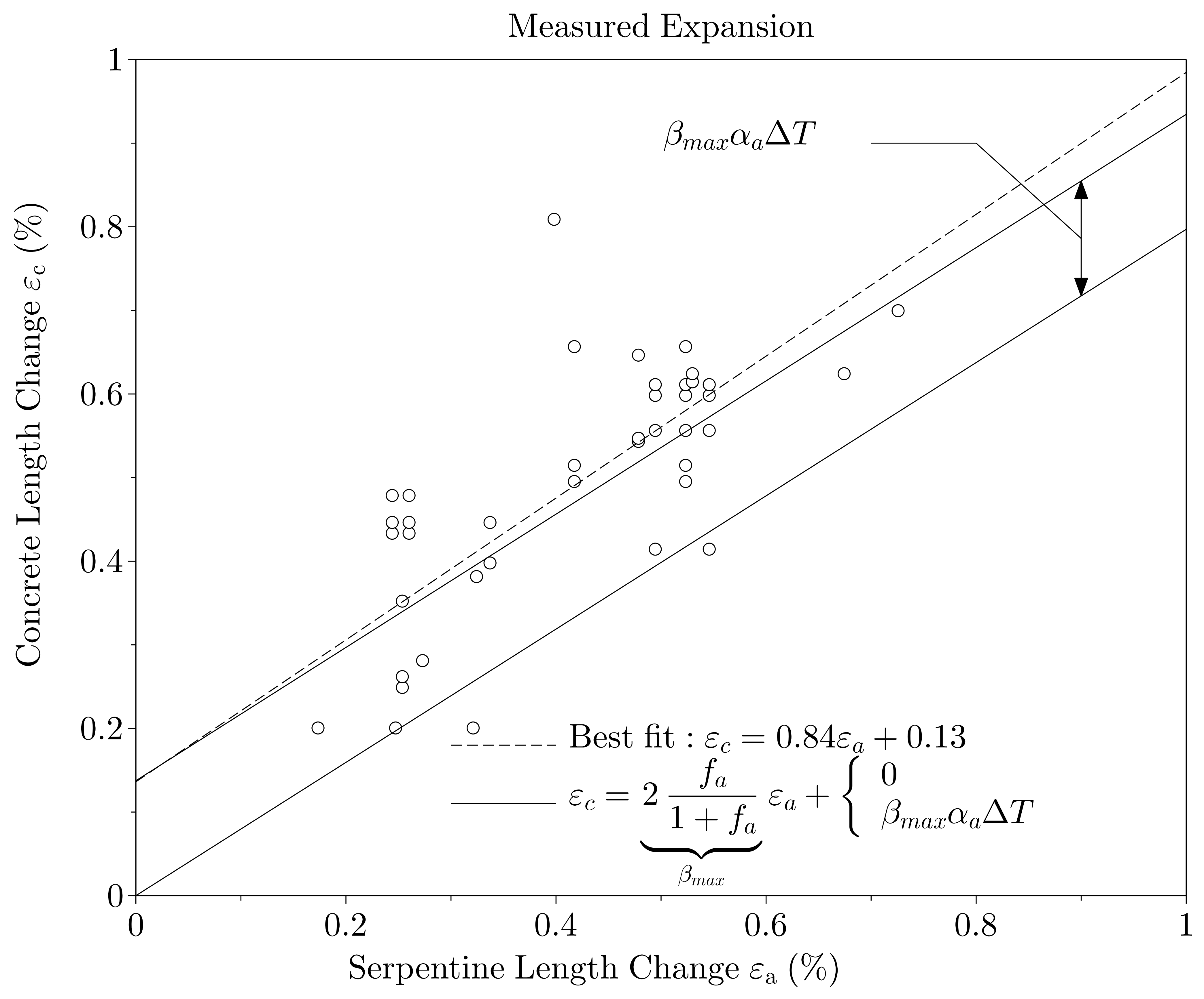




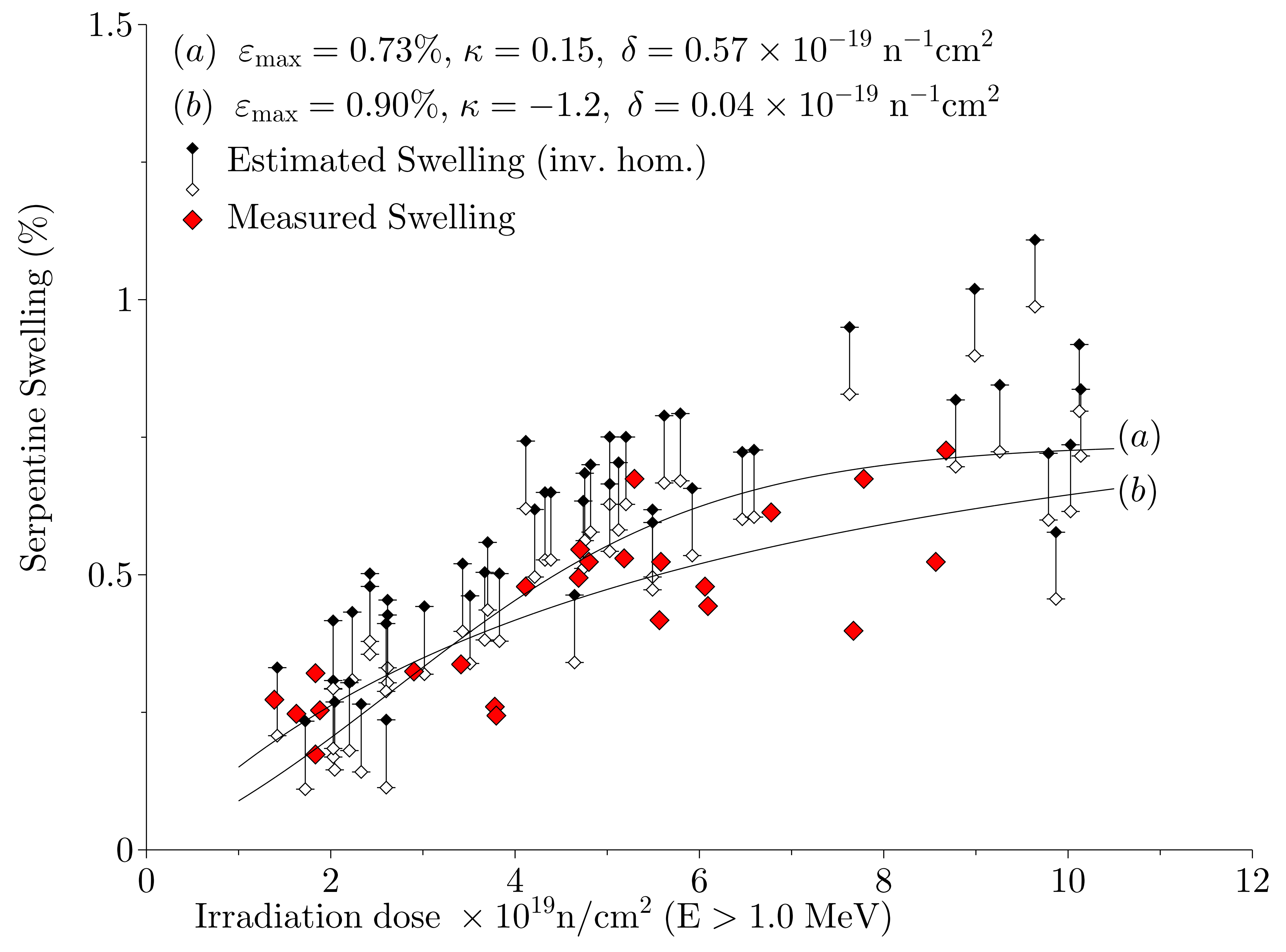




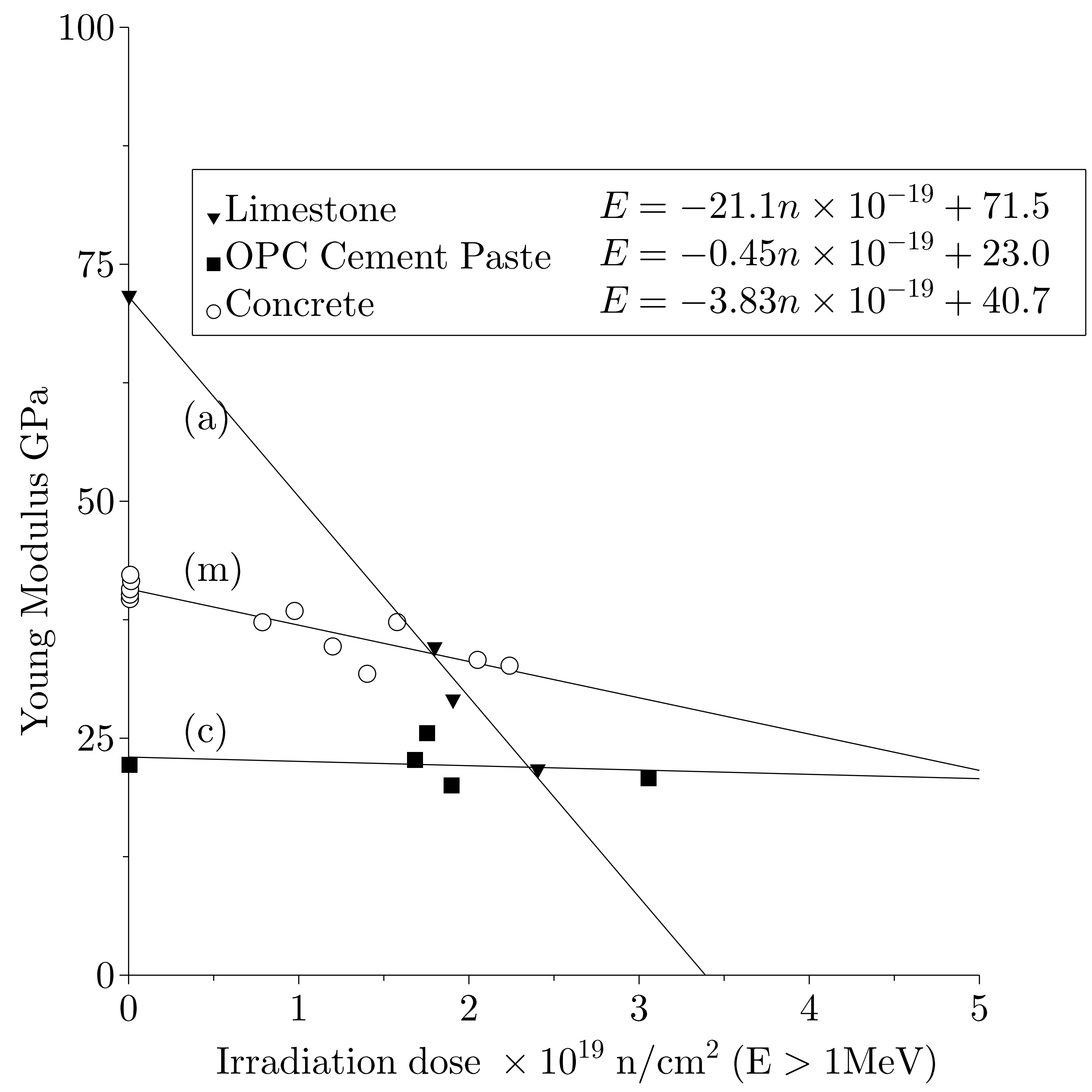




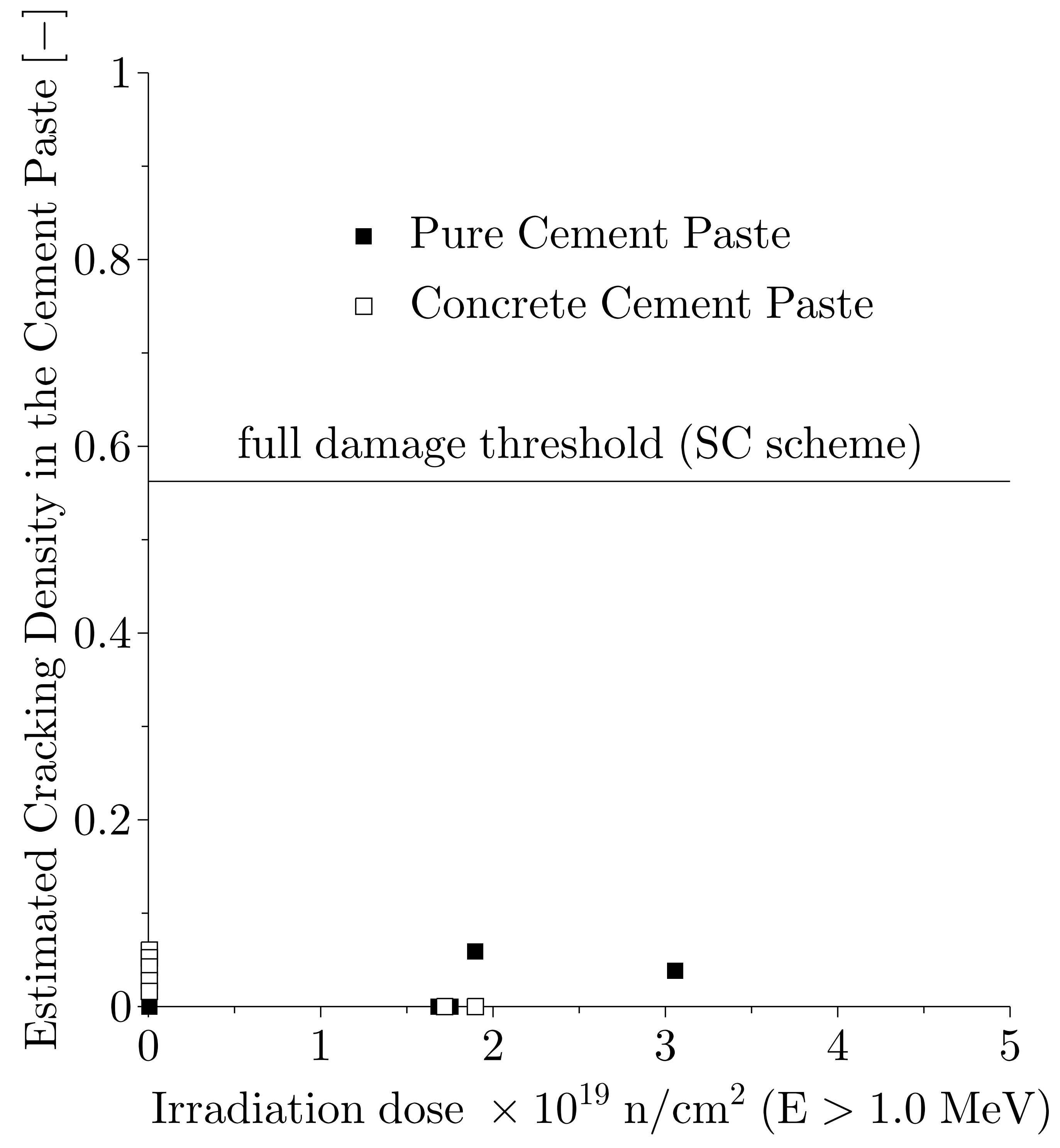




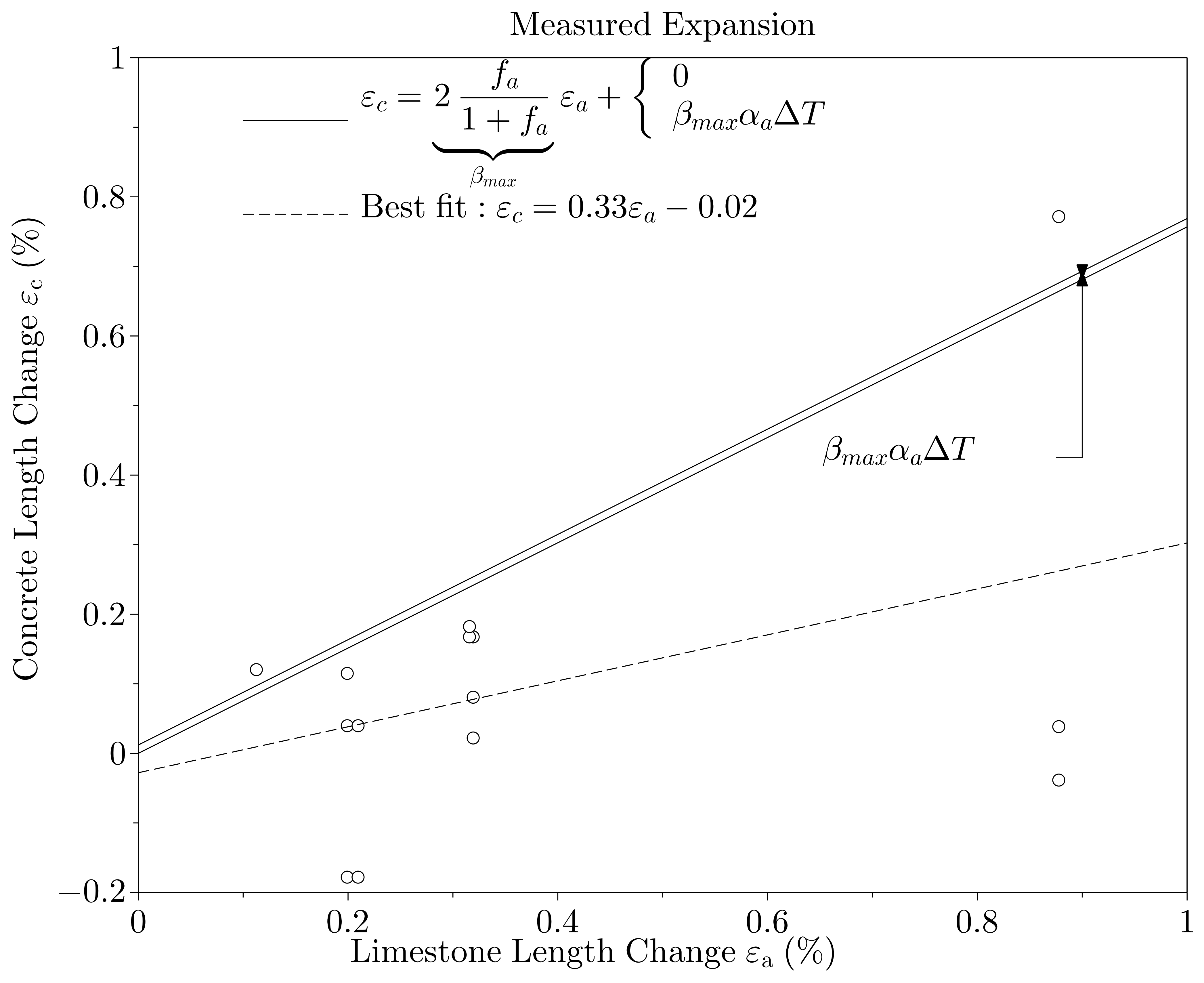




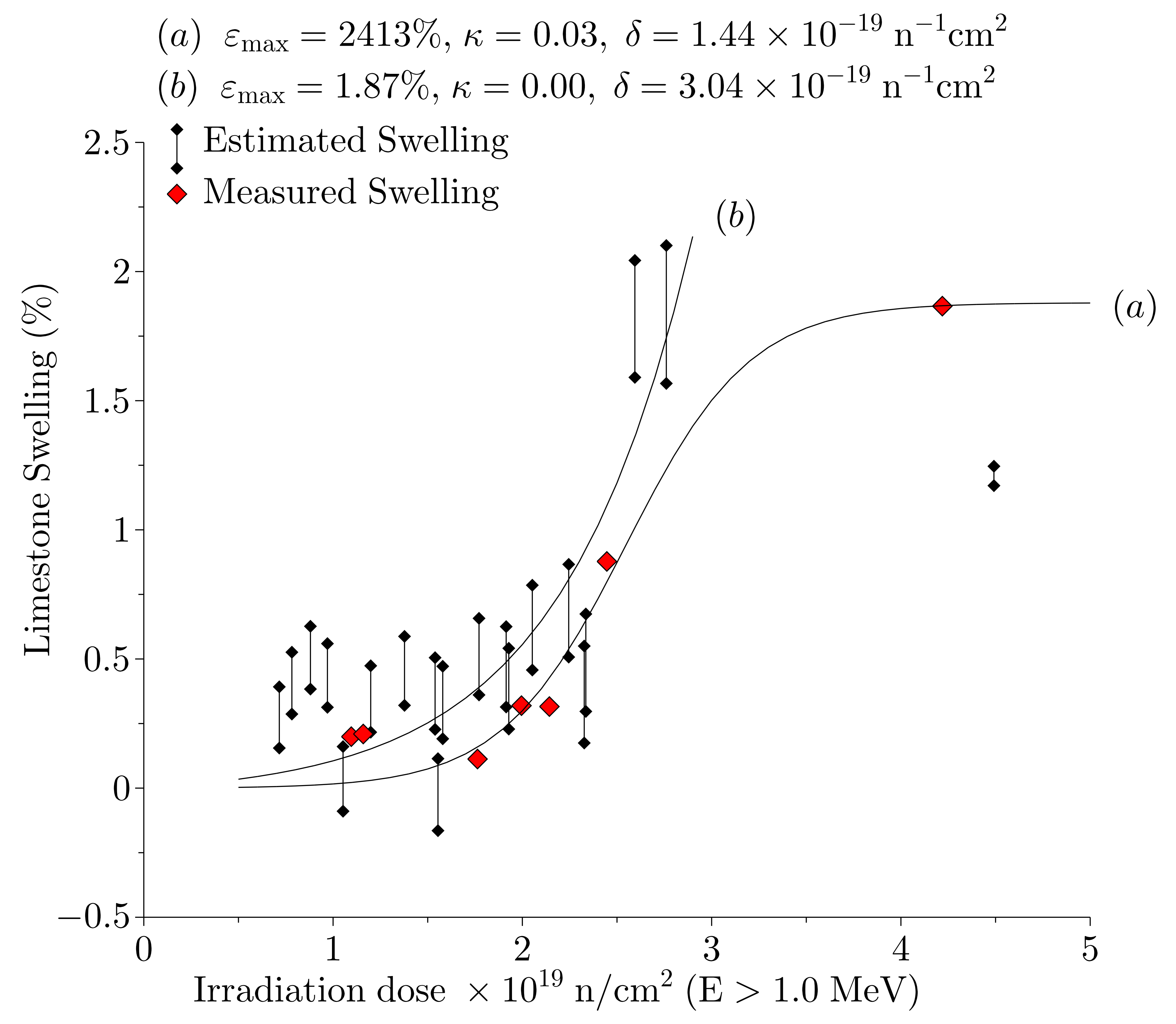




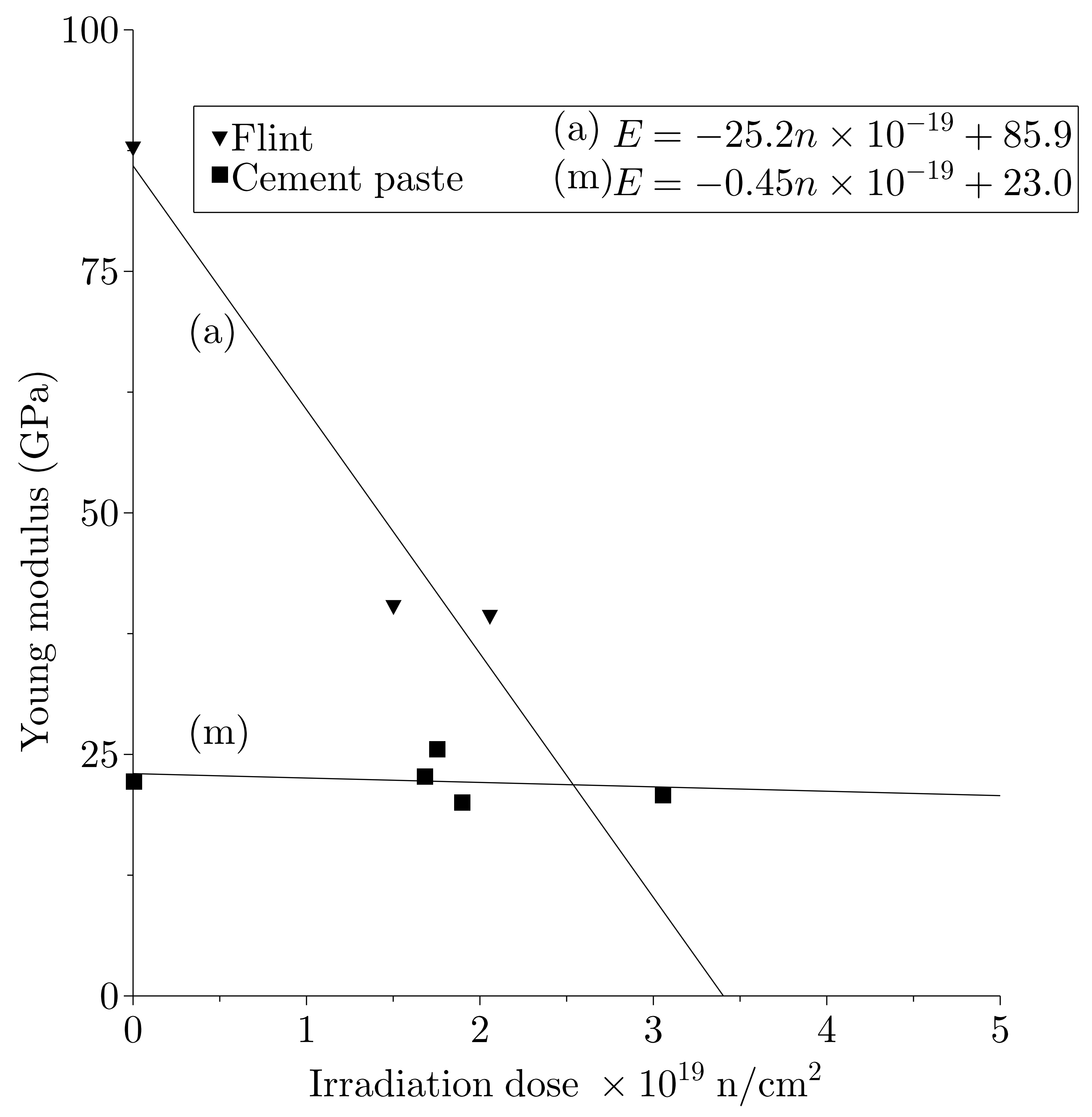




\section{Measured expansion}

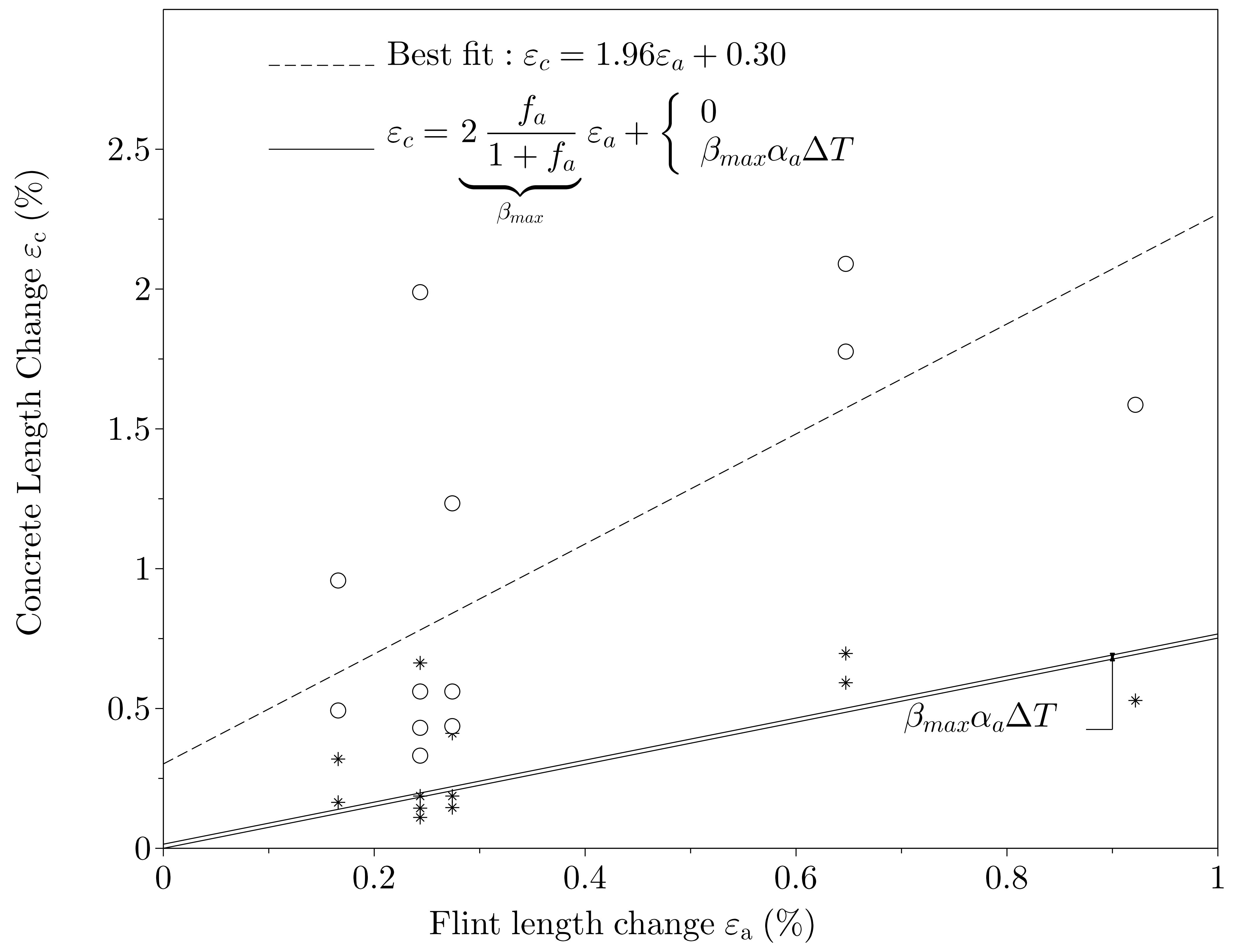




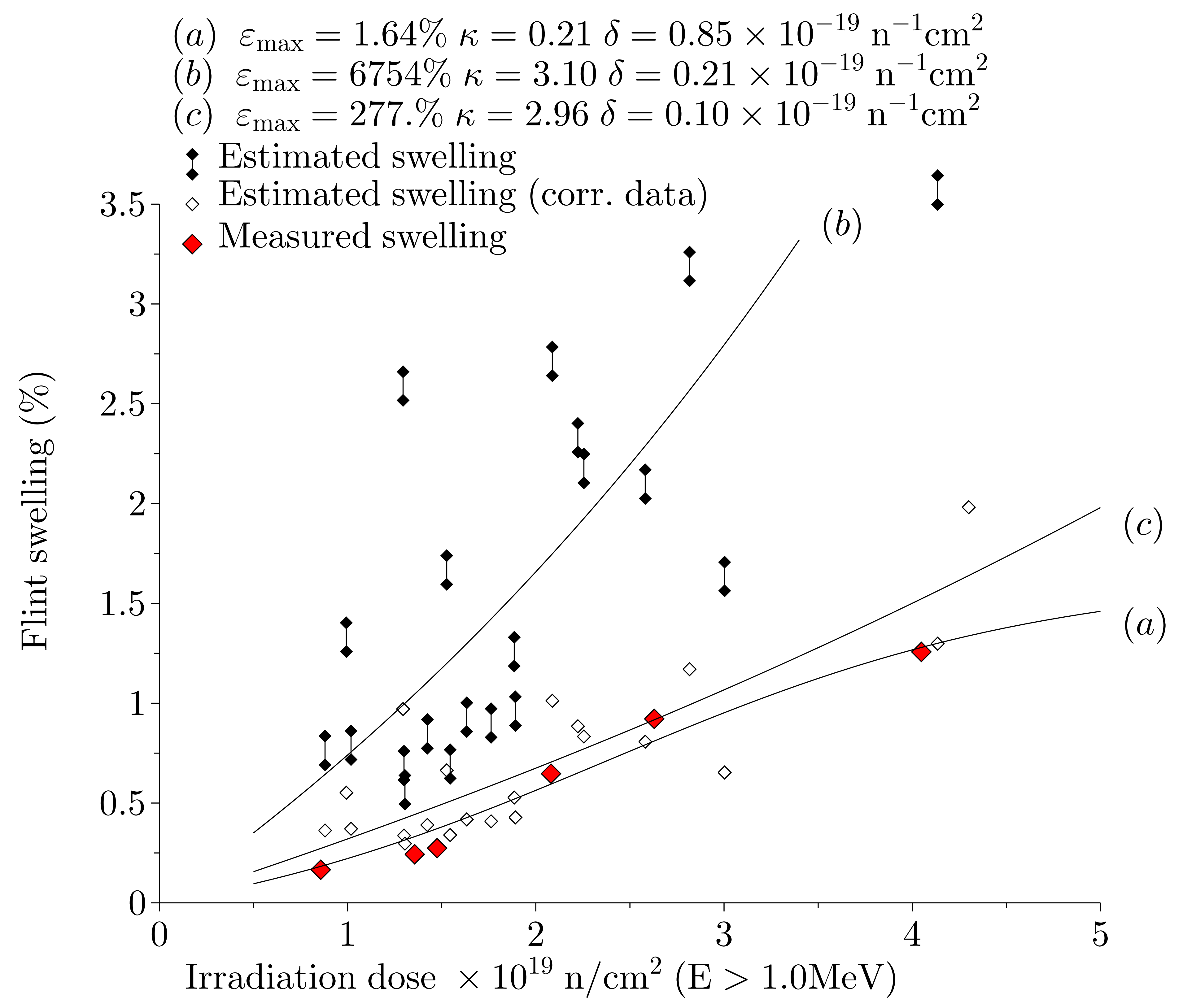


Serpentine Aggregate - [Elleuch et al., 1971]

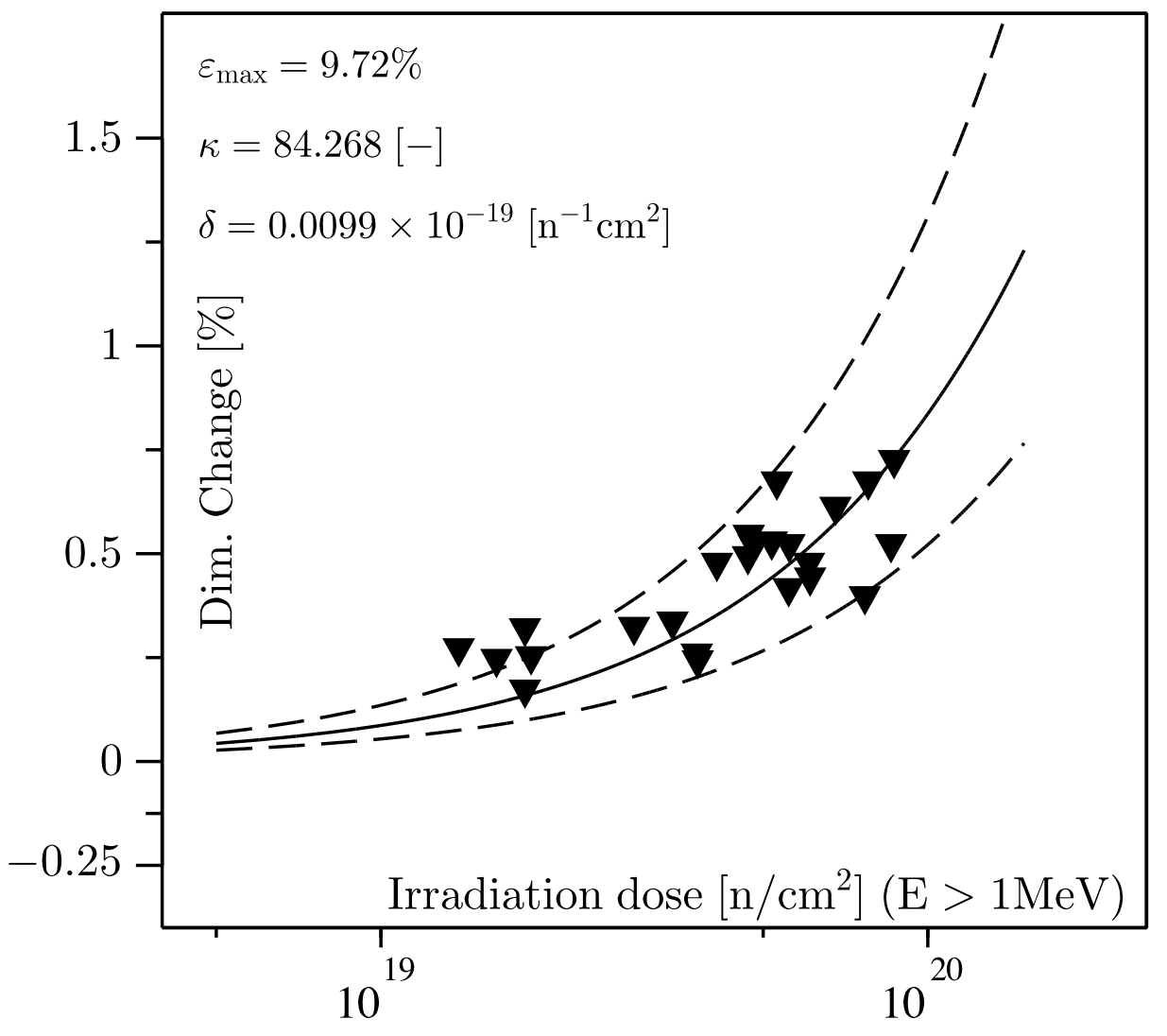

Limestone Aggregate - [Kelly et al., 1969]

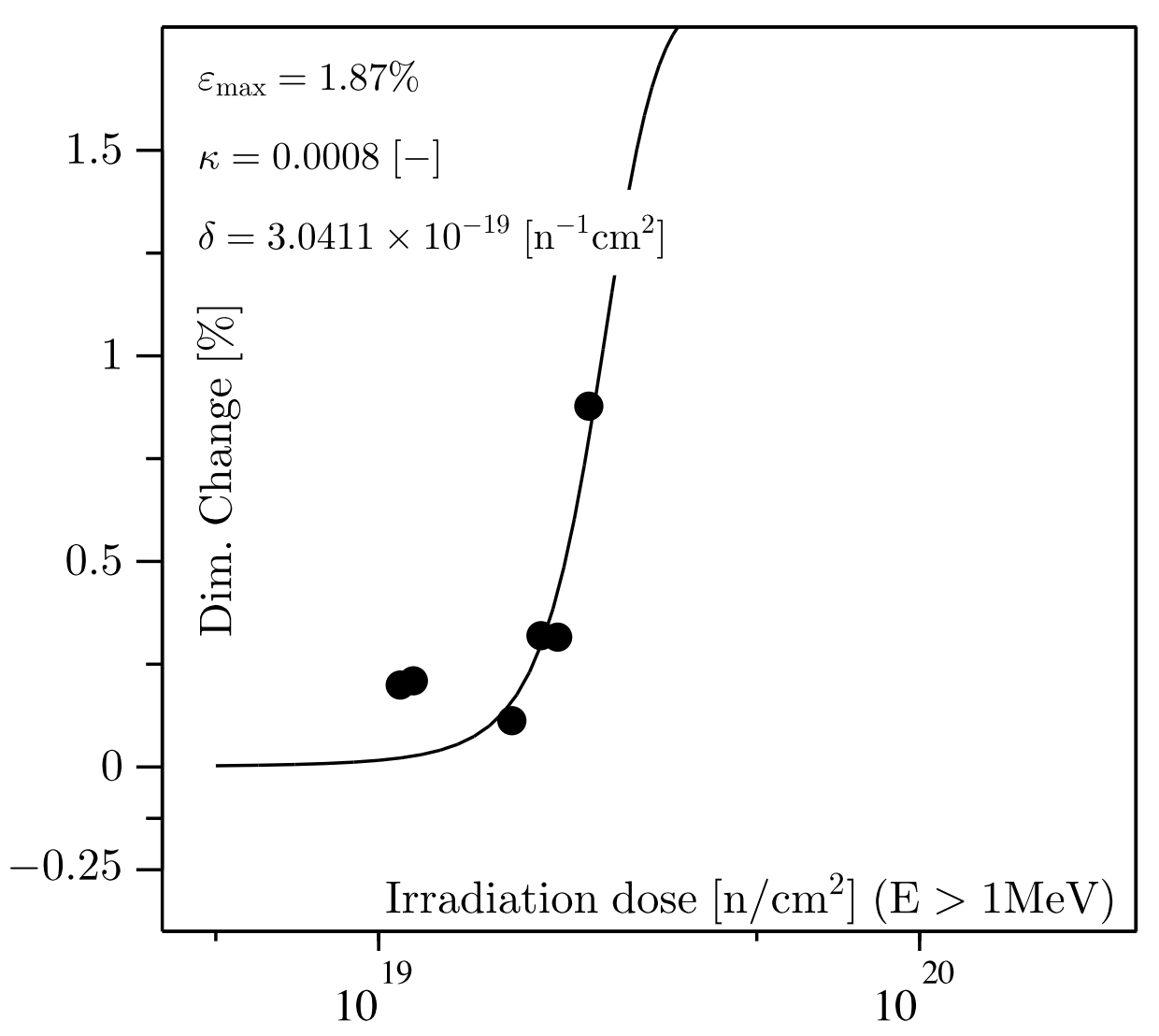

Flint Aggregate - [Kelly et al., 1969]

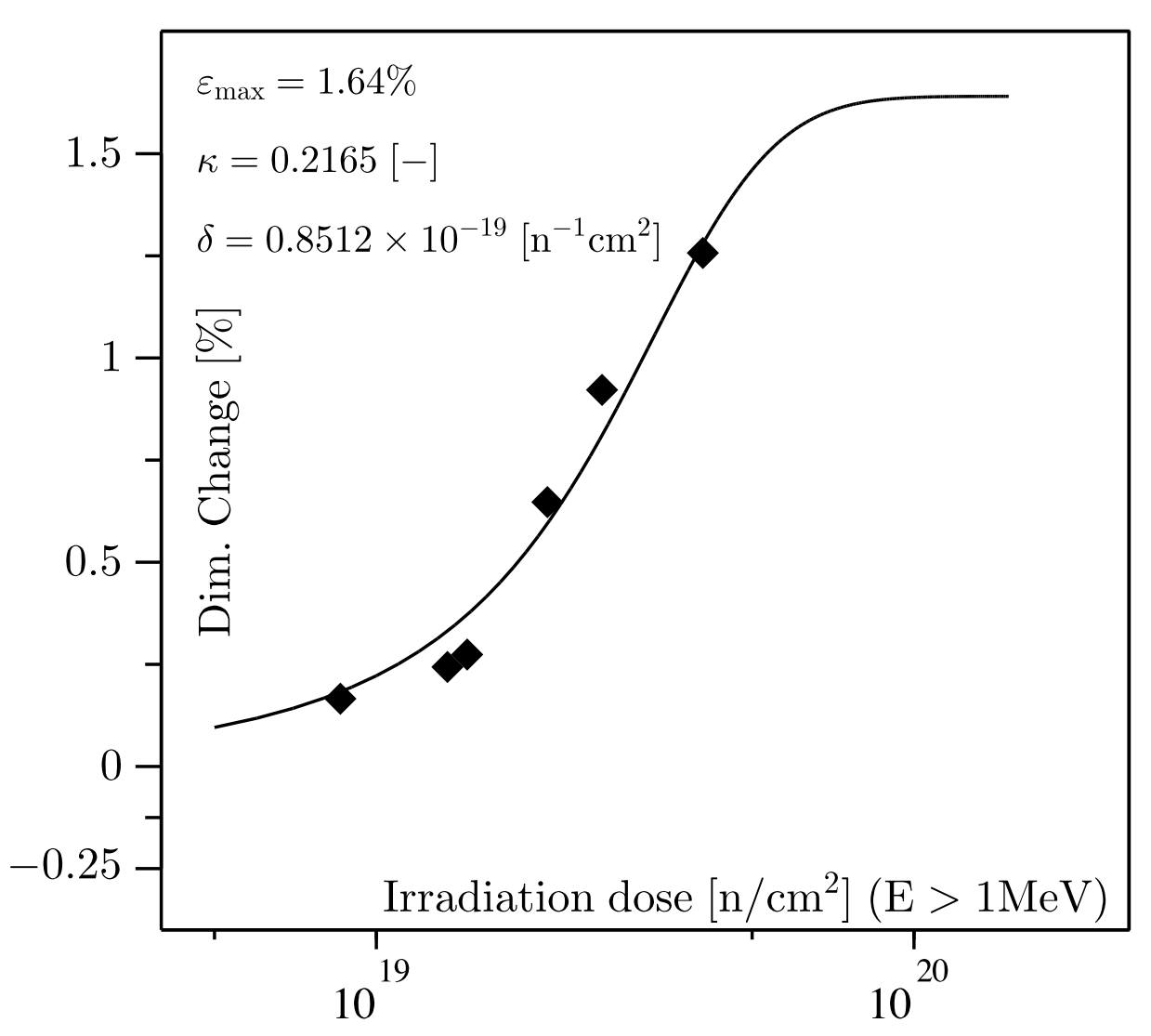

Serpentine Concrete - [Elleuch et al., 1971]

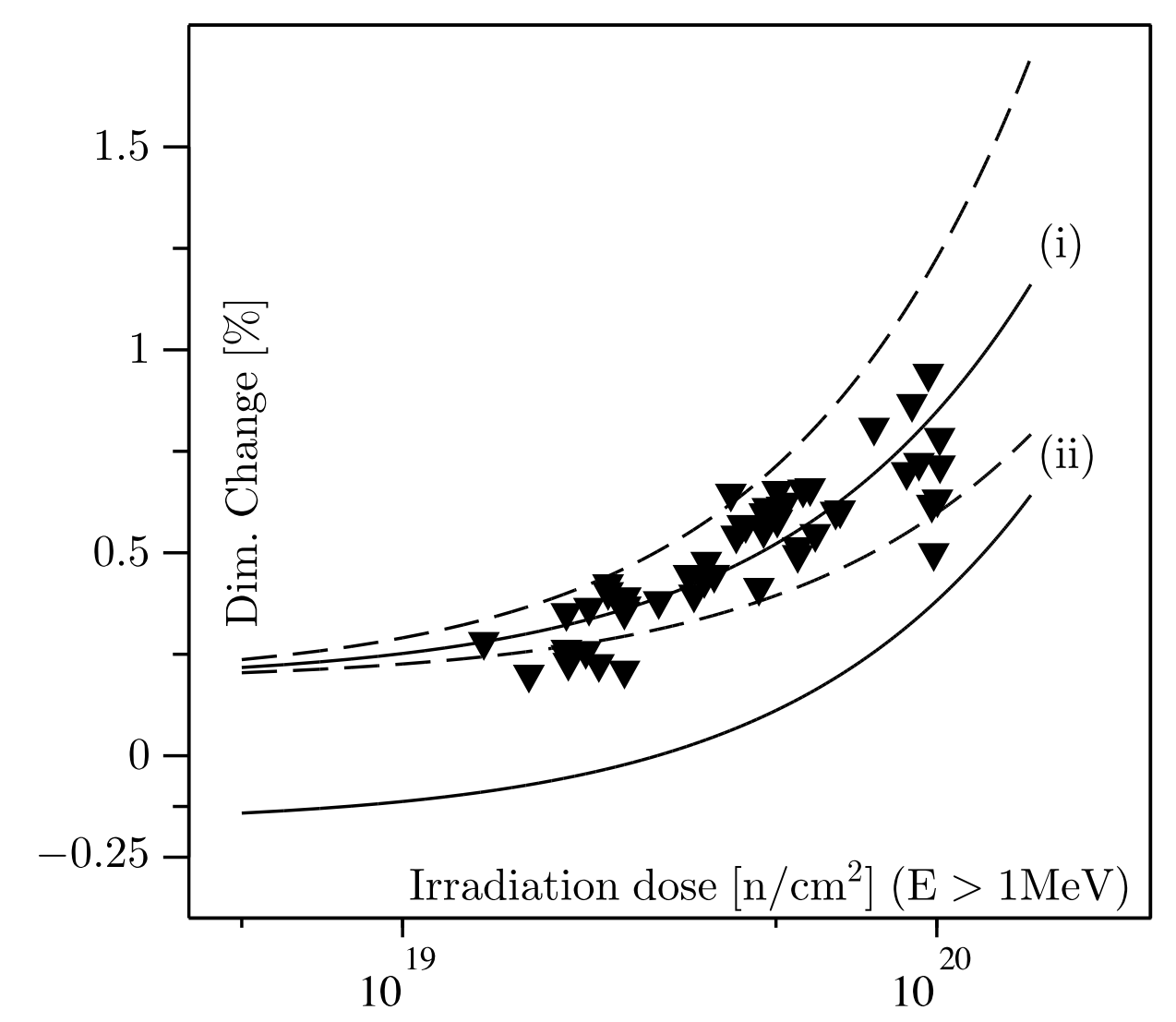

Limestone Concrete - [Kelly et al., 1969]

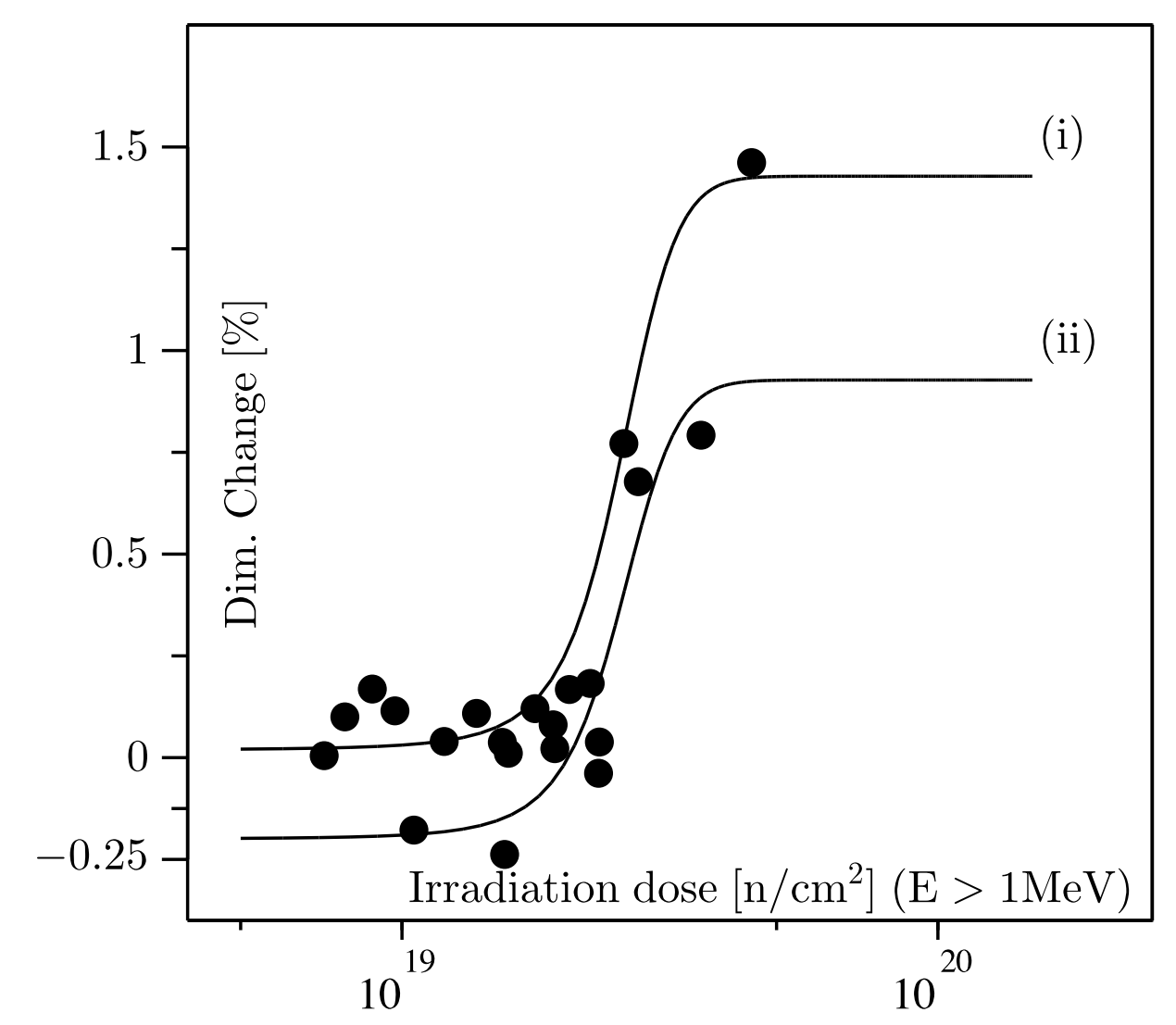

Flint Concrete - [Kelly et al., 1969]

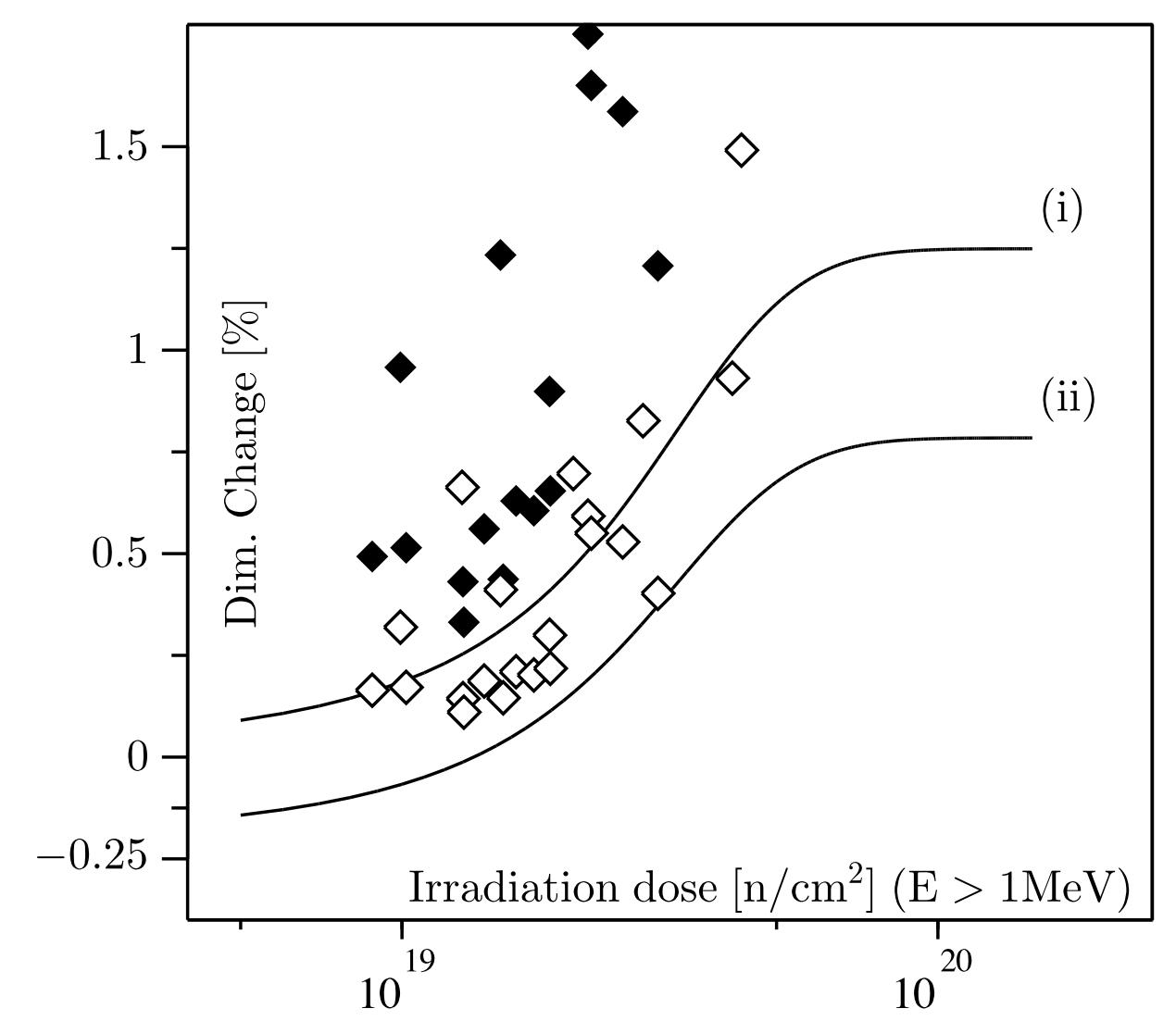

